\title{
Summer High Temperature Extremes in Southeast China: Bonding with the El Niño-Southern Oscillation and East Asian Summer Monsoon Coupled System
}

\author{
WEIWEN WANG \\ Guy Carpenter Asia-Pacific Climate Impact Centre, School of Energy and Environment, City University \\ of Hong Kong, Hong Kong, and State Key Laboratory of Tropical Oceanography, South China Sea \\ Institute of Oceanology, Chinese Academy of Sciences, Guangzhou, China \\ WEN ZHOU \\ Guy Carpenter Asia-Pacific Climate Impact Centre, School of Energy and Environment, City University \\ of Hong Kong, Hong Kong, China \\ DELIANG CHEN \\ Department of Earth Sciences, University of Gothenburg, Gothenburg, Sweden
}

(Manuscript received 5 September 2013, in final form 12 January 2014)

\begin{abstract}
This study investigates summer high temperature extremes (HTEs) in southeast China and their linkage with the El Niño-Southern Oscillation (ENSO) and atmospheric circulations in the East Asian summer monsoon (EASM). An interdecadal change in HTEs associated with the abrupt shift of the ENSO-monsoon climate in the late 1980s is demonstrated. Before this interdecadal shift, the interannual variability of HTEs was linked mainly to temperature adjustments associated with the meridional displacement of the East Asian jet stream (EAJS), whereas after the shift HTEs were found to follow an ENSO cycle, which may be due to intensified and persistent ENSO activities, tropical Indian Ocean (TIO) warming, and changes in atmospheric teleconnections. Impacts of the EAJS, the South Asian high (SAH), and the western North Pacific subtropical high (WNPSH) on HTEs are further investigated based on empirical orthogonal function (EOF) analysis. It is found that mainly the first leading EOF mode with a homogeneous spatial pattern shows dominance before the interdecadal shift, whereas both of the first two leading EOF modes show dominance after the interdecadal shift. A possible mechanism of how HTEs in southeast China are linked to the EAJS, the SAH, and the WNPSH in the ENSO-monsoon coupled system is proposed.
\end{abstract}

\section{Introduction}

Extreme climatic events have received more and more attention in recent decades due to their direct and disastrous impact on human society and regional ecosystems. Heat waves are a complex form of these climatic extremes and have been occurring with increasing frequency, severity, and duration under the background of global warming. Throughout this study, we use the term "high temperature extremes" (HTEs) to represent days with a daily maximum temperature (DMT) in excess of a specific high threshold, namely hot days, and

Corresponding author address: W. Zhou, Guy Carpenter AsiaPacific Climate Impact Centre, School of Energy and Environment, City University of Hong Kong, Hong Kong 00852, China.

E-mail:wenzhou@cityu.edu.hk investigate the interdecadal change and interannual variability in their occurrence. Based on this definition, linkages with large-scale atmospheric and oceanic forcing, which are usually dominant, can be clearly described. Other forcings, such as land use and urbanization, are not included in the scope of this study.

Previous studies of HTEs in China have focused mostly on long-term trends in recent decades (e.g., Gong et al. 2004; Qian and Lin 2004; Qian et al. 2011b; Su et al. 2006; Yan et al. 2011; You et al. 2008). It is found that significant increasing trends occur in most regions of China except east-central China, which displays significant decreasing trends (Zhai and Pan 2003; Zhang et al. 2008; Zhou and Yu 2006). Natural and anthropogenic forcing are possible reasons for this summer surface cooling in east-central China ( $\mathrm{Li}$ et al. 2007; Menon et al. 2002; Ueda et al. 2006; Xu 2001). Natural forcing studies 

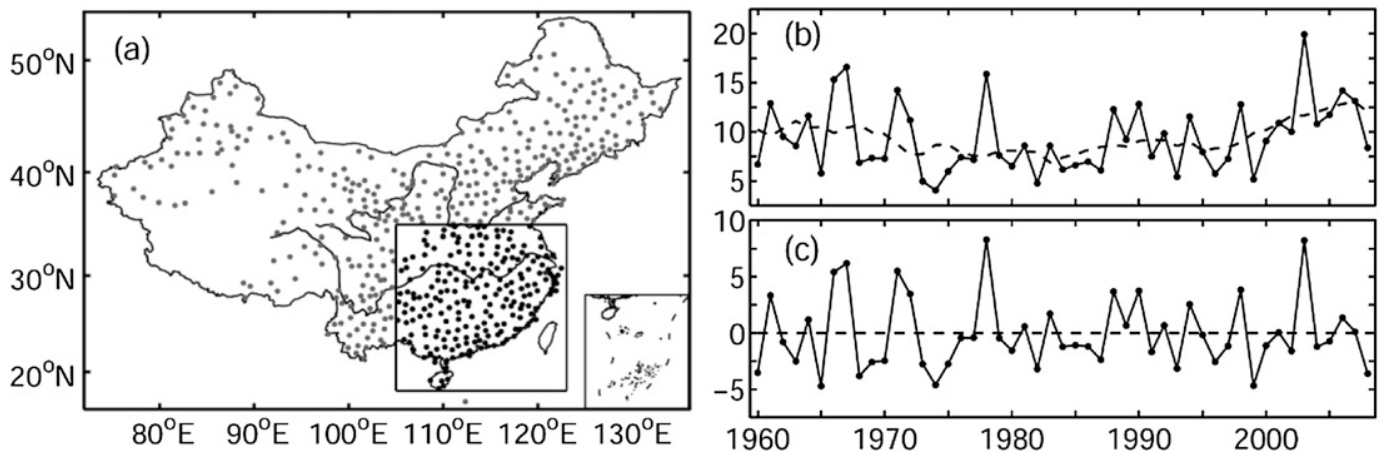

FIG. 1. (a) Map of China with dots showing gauge stations. The box represents the domain of southeast China in this study that covers 204 gauge stations. (b) Time series of HTEs averaged over southeast China. Dashed line indicates 9-yr running mean. (c) Time series of HTEs after the 9-yr running mean is removed.

have emphasized that this summer cooling trend downstream of the Tibetan Plateau is associated with the southward displacement of the upper-level westerly jet stream and the weakening of the East Asian summer monsoon (EASM) (Ding et al. 2009; X. Wang et al. 2013; Xin et al. 2006; Yu et al. 2004; Yu and Zhou 2007; Zhou et al. 2006). A numerical study suggested that the Pacific decadal oscillation-related SST is responsible for this EASM weakening ( $\mathrm{Li}$ et al. 2010). A review of the multidecadal variability of the EASM has been presented by Zhou et al. (2009a).

The coupled effects of the El Niño-Southern Oscillation (ENSO) and the EASM on the interannual variability of the East Asian climate have been emphasized (Wang et al. 2001; Wu et al. 2009; Yuan et al. 2008; Zhou and Chan 2005; Zhou et al. 2005; Zhou et al. 2009b). The influences of this coupled system on precipitation over the East Asia-western North Pacific (WNP) region and south China have been widely discussed (Chan and Zhou 2005; X. Li et al. 2011; Li and Zhou 2012; Wang et al. 2012; Wang and Wang 2013). Previous studies have suggested that this coupled system affects HTEs in China mainly through one of its most important components, the WNP subtropical high (WNPSH). An enhanced WNPSH, in terms of anticyclonic anomalies in the geopotential height centered over the Yellow Sea and the Korean Peninsula, results in rapid warming over the Eurasian continent and an anomalously high frequency of HTEs in eastern China (Ding et al. 2010; You et al. 2011). An anticyclonic anomaly in the WNP is triggered by warming in the tropical Indian Ocean (TIO) in the summer following the mature phase of El Niño (Du et al. 2009; Wu et al. 2009; Xie et al. 2009; Yang et al. 2007) and is favorable for HTEs in south China (Hu et al. 2011; Hu et al. 2012).

Our recent study revealed the linkage of HTEs in southeast China (enclosed by the box in Fig. 1a) with the
East Asian jet stream (EAJS) and the circumglobal teleconnection along the waveguide of the westerly jet (W. Wang et al. 2013). On an area-averaged basis, HTE occurrences are obviously connected with the displacement of the EAJS, which is due to the coupled dynamics of tropospheric temperatures and westerlies in the tropopause (e.g., X. Wang et al. 2013). However, geographic distinctions between HTEs in southeast China may require coupled reinforcements. In this study, we aim to delineate how HTEs in southeast China connect with large-scale atmospheric forcing in the coupled system of ENSO-EASM. Note that July-August (JA) is used to represent boreal summer in the investigations of HTEs and associated atmospheric anomalies, as our preceding analyses (not shown) suggest that their linkages are clearer compared to an average in JuneAugust (JJA).

The manuscript is organized as follows: Data and analysis methods used in this study are described in the next section. Major results are presented in section 3, including the interdecadal change of HTEs in southeast China in section $3 \mathrm{a}$, interannual variability associated with the ENSO cycle in section 3b, and a discussion of how coupled atmospheric systems in the EASM region affect geographic differences in HTEs in section 3c. The final section summarizes our main findings with some concluding remarks.

\section{Data and methodology}

Homogenization of observation data is a challenge in climate change studies, especially in climatic extreme studies (e.g., Yan et al. 2010). A homogenized historical temperature dataset for China including a homogenized daily temperature series spanning from 1960 to 2008 (Li and Yan 2009,2010) is used in this study. The geographic distribution of the 549 stations in this dataset is shown in 
Fig. 1a. The domain of southeast China in this study, south of $35^{\circ} \mathrm{N}$ and east of $105^{\circ} \mathrm{E}$, is shown in the box in Fig. 1a. For the definition of HTEs, the 90th percentile of JA DMT at each station, derived from a climatological period of 1961-90, is taken as the threshold. Different base periods will result in different mean annual cycles and anomalies in a changing climate (Qian et al. 2011a). A base period of 1961-90 is suggested by the Expert Team for Climate Change Detection Monitoring and Indices (ETCCDMI) and is commonly used in analyzing climate extremes (e.g., Alexander et al. 2006; Donat et al. 2013). For percentile transformation we adopt the empirical formula method introduced by Beard (1943) and described in detail by Jenkinson (1977). A binomial filter is applied to the series of percentiles to remove synoptic turbulence (e.g., Jones et al. 1999). An occurrence of HTE is identified when DMT is above the threshold.

Sea surface temperature (SST) data are from the National Oceanic and Atmospheric Administration (NOAA) extended reconstructed SST (ERSST) (Smith et al. 2008), which was constructed using the most recently available International Comprehensive OceanAtmosphere Data Set (ICOADS) SST data. NOAA ERSST version 3 data are provided by the NOAA Office of Oceanic and Atmospheric Research Earth System Research Laboratory, Physical Science Division (OAR/ESRL/PSD), Boulder, Colorado, from their website (http://www.esrl.noaa.gov/psd/). Geopotential height and zonal wind velocity in pressure levels from the National Centers for Environmental PredictionNational Center for Atmospheric Research (NCEPNCAR) reanalyses (Kalnay et al. 1996; Kistler et al. 2001) are used for analysis of atmospheric circulation anomalies associated with HTEs in the ENSO-EASM coupled system. SST anomalies (SSTAs) averaged over the equatorial eastern Pacific $\left(5^{\circ} \mathrm{S}-5^{\circ} \mathrm{N}, 120^{\circ}-170^{\circ} \mathrm{W}\right)$ are used to track ENSO, which is referred to as the Niño-3.4 index. We define the TIO as the domain enclosed within $20^{\circ} \mathrm{S}-20^{\circ} \mathrm{N}, 40^{\circ}-100^{\circ} \mathrm{E}$. SSTAs averaged over the TIO are referred to as the TIO index. We characterize the WNPSH at the 500-hPa geopotential height enclosed within $20^{\circ}-25^{\circ} \mathrm{N}, 125^{\circ}-140^{\circ} \mathrm{E}$ and the South Asian high $(\mathrm{SAH})$ at the $150-\mathrm{hPa}$ geopotential height enclosed within $20^{\circ}-35^{\circ} \mathrm{N}, 60^{\circ}-95^{\circ} \mathrm{E}$.

The present study focuses on year-to-year variations; a 3-month running mean is first applied to all atmospheric and SST fields, so any pronounced intraseasonal variability is removed. To remove long-term variations, the linear trend or a 9-yr running mean is deducted in the parameters. The reflective (symmetric) conditions are utilized in the 9-yr running mean to retain the end points. The time series of HTEs averaged over southeast
China is given in Fig. 1b. The dashed line represents the 9-yr running mean. The time series of area-averaged HTEs with the 9-yr running mean removed is shown in Fig. 1c. The $r$ test is used as the confidence test of correlation and the Student's $t$ test is used as the confidence test of composite analysis. The Mann-Kendall test (Kendall 1955; Mann 1945) is applied to determine the year when interdecadal shift occurs in the linkage between HTEs and the El Niño index. This nonparametric statistical method can sometimes violate the Gaussian assumption and is widely used to test the significance of linear trends for climate extremes (e.g., Von Storch and Navarra 1995; Qian and Zhou 2014).

\section{Results}

Empirical orthogonal function (EOF) analysis is applied to characterize the temporal and spatial patterns of HTEs in southeast China. Only the first two leading modes are well separated from other modes according to North et al. (1982). Spatial patterns of the first two leading EOF modes are shown in Fig. 2. The first mode (EOF1) explains $44.6 \%$ of the total explained variance, while the second mode (EOF2) explains $15.2 \%$. EOF1 exhibits a uniform spatial pattern with a maximum variance center over the lower Yangtze River valley, whereas EOF2 shows an opposite southeast-northwest pattern. The first and second leading principal components (PC1 and PC2) are given in Figs. 2c and 2d, respectively. Correlation of the area-averaged time series given in Fig. 1c with PC1 and PC2 is 0.99 and 0.08 , respectively. Wavelet analysis (Torrence and Compo 1998) is applied to represent the power spectrum of these two leading PCs (Fig. 3). Generally, both PCs reveal a prominent quasi-biennial signal in their global spectrum, but decadal differences in PC1 and PC2 are obvious. In the following discussion, sections $3 \mathrm{a}$ and $3 \mathrm{~b}$ will focus mainly on $\mathrm{PC} 1$, while section $3 \mathrm{c}$ will consider both $\mathrm{PC} 1$ and $\mathrm{PC} 2$.

\section{a. Interdecadal change}

The abrupt regime shift in global climate in the late 1970s, denoted by a global-scale change in SST and atmospheric teleconnections, has been recognized for decades (Nitta and Yamada 1989; Trenberth 1990). With changes in the period, amplitude, and spatial structure of ENSO (An and Wang 2000; Wang 1995; Wang and An 2002; Wang et al. 2009), the ENSOEASM relationship has strengthened (Wang et al. 2008). The question may arise as to whether there is any interdecadal change in the relationship between ENSO and HTEs in southeast China. A quick look at the time series of PC2 suggests that the magnitude of PC2 is 
(a) EOF1: $44.6 \%$

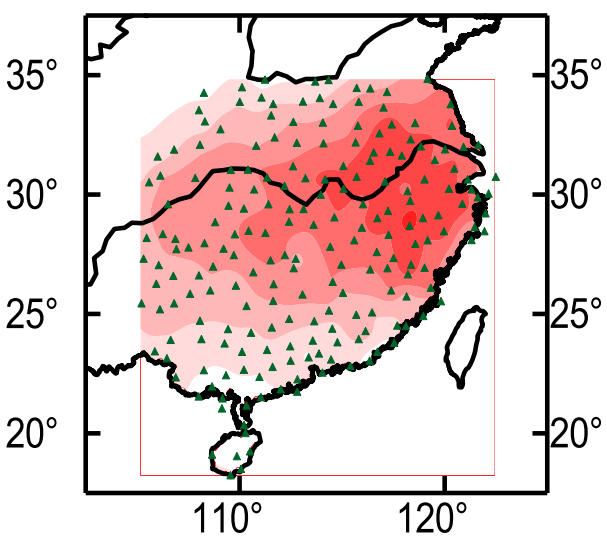

(c) PC1: $44.6 \%$

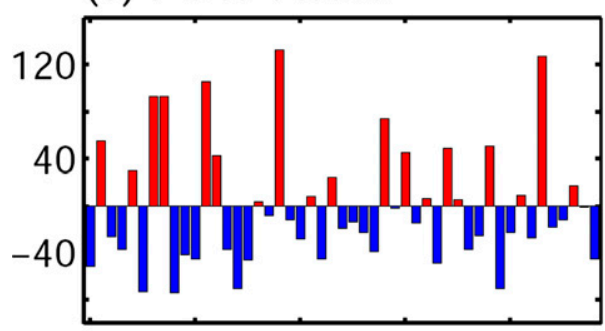

19601970198019902000 (b) EOF2: $15.2 \%$

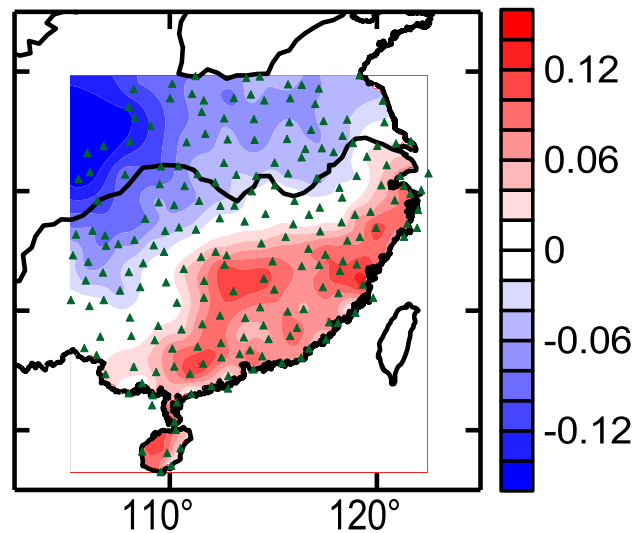

(d) PC2: $15.2 \%$

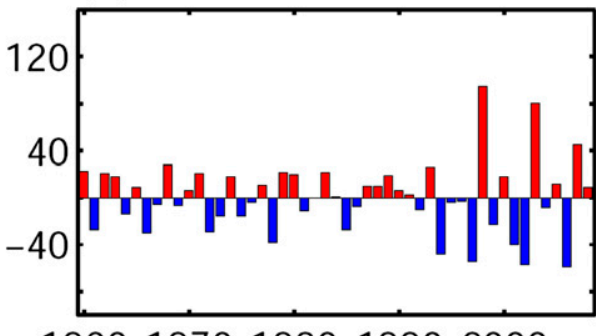

19601970198019902000

FIG. 2. (a),(b) The first two leading EOF modes, respectively. (c),(d) Corresponding PCs of HTEs in southeast China, respectively. The variance is explained by the leading modes: $44.6 \%$ and $15.2 \%$.

rather small before the 1990s. After the 1990s, it noticeably enlarges. Meanwhile, the wavelet power spectrum of the first two leading PCs may imply an abrupt change around the late 1980s to the early 1990s. Before this time, the interannual signal is more significant in $\mathrm{PC} 1$, whereas afterward it is more significant in PC2.

The Indian Ocean may play an important role in the coupled climate effects of the monsoon and ENSO. In Fig. 4a, the blue and red dashed lines represent the 21-yr running mean of the Niño-3.4 and TIO indices, respectively. The Niño-3.4 index here is in DecemberFebruary (DJF)(0), the mature phase of El Niño. The TIO index is in March-May(MAM)(1), when the Indian Ocean warming reaches its peak following an El Niño event (Xie et al. 2009; Yang et al. 2007). Decadal and longer variations of these dashed lines are retained here to show the strengthening of ENSO activities and the increasing trend of Indian Ocean warming. It is obvious that due to the warming trends of the SSTA index in both the ENSO region and the TIO, their impact on the southeast China HTEs also increases remarkably, as shown by the solid lines in Fig. 4a. Note that these correlations are calculated with decadal signals removed in the time series to retain only interannual relationships.
The connections of HTEs with both the Niño-3.4 index and the TIO index increase dramatically and go above the $90 \%$ confidence levels after the late 1980s. The Mann-Kendall test is applied to the 21-yr running correlation between PC1 of HTEs and the Niño-3.4 index (i.e., the solid blue line in Fig. 4a) to identify the year of the interdecadal shift. The result is shown in Fig. 4b, which indicates that the interdecadal change happened in $1987 / 88$. This is consistent with a recent study by $\mathrm{Hu}$ et al. (2013), which suggested that ENSO had an enhanced influence on August HTEs over the southern Yangtze River valley in the late 1980s. Here we demonstrate that this interdecadal shift can be found in the JA HTEs in southeast China. So the preshift and postshift periods are determined to be 1960-87 and 19882008, respectively. In the following discussion, we will use the terms POST epoch and PRE epoch to represent these two periods. The correlation of SSTAs with PC1 of JA(1) HTE in the POST and PRE epochs is given in Fig. 5. It is found that the linkage between HTEs and SST in the POST epoch is strong, whereas in the PRE epoch it is rather weak. Correlations between HTEs and SSTAs in the PRE epoch are mostly not significant. Similar results can be found in Fig. 6a, in which correlations of 
(a)PC1 Wavelet Power Spectrum

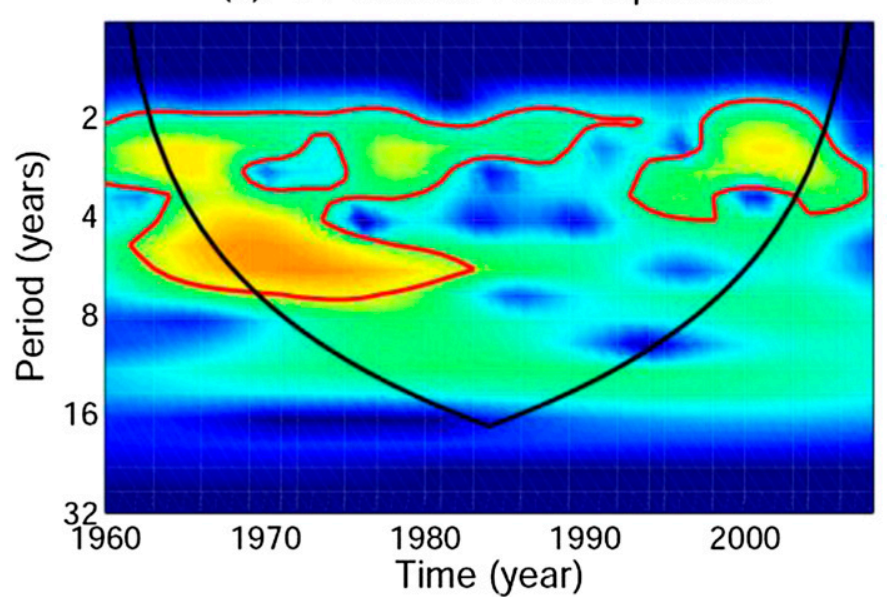

(c)PC1 Wavelet Power Spectrum

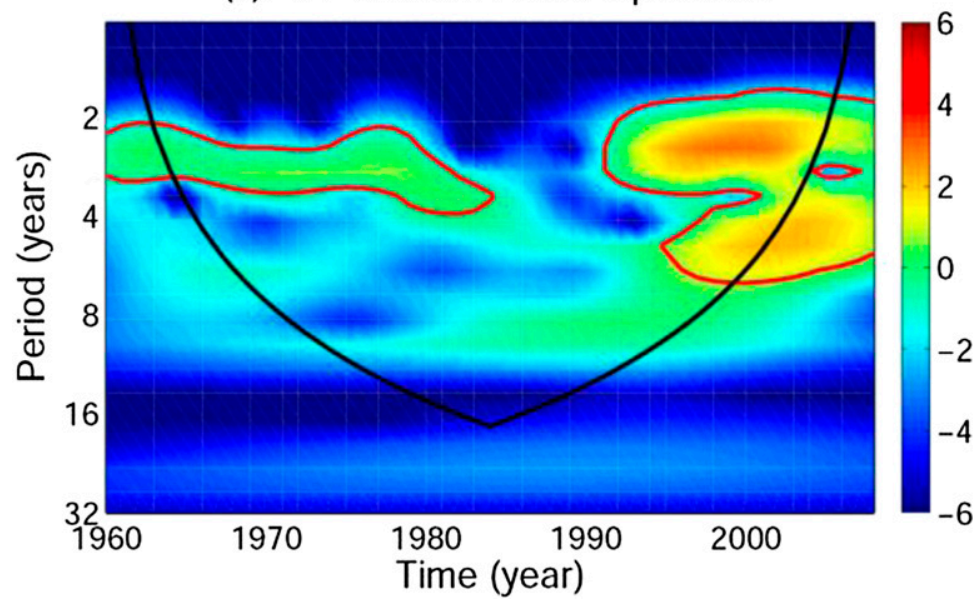

(b)PC1 Global Spectrum
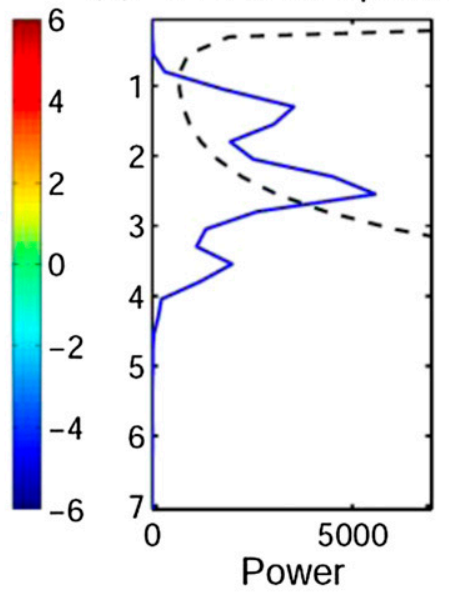

(d)PC2 Global Spectrum

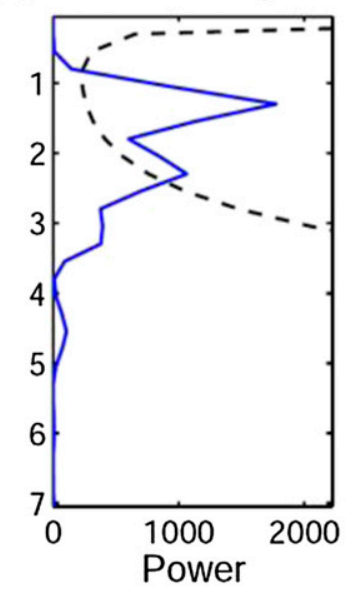

FIG. 3. Wavelet power spectrum of (a) PC1 and (c) PC2 of HTEs in southeast China and the global spectrum for (b) PC1 and (d) PC2. The black line in (a),(c) denotes the cone of influence. Red lines in (a),(c) and dashed lines in (b),(d) denote values over the $95 \%$ confidence level.

HTEs with the Niño-3.4 and TIO indices are all below the $95 \%$ confidence level in the PRE epoch. In contrast, significant correlations of HTEs with the Niño-3.4 and TIO indices may follow an ENSO cycle in the POST epoch, which will be further investigated in section $3 \mathrm{~b}$.

The influences of SST anomalies on surface extremes should correlate with atmospheric circulation anomalies. Figure $6 \mathrm{~b}$ is the same as Fig. $4 a$, but for simultaneous WNPSH (blue lines) and SAH (red lines) indices. As two important atmospheric circulations in the EASM system, both the WNPSH and the SAH intensify dramatically in association with the Indian Ocean warming after the late 1970s (e.g., Huang et al. 2011; Zhou et al. 2009 c). Correlations of HTEs with the SAH index are found to be greater than those with the WNPSH index. The correlation of HTEs with the upper-level SAH is higher than that with the midlevel WNPSH, which may be due to the different characteristics of these two systems. The WNPSH performs a seasonal mean state march and has complex anomalies in response to various kinds of thermodynamic and dynamic forcings ( Wu et al. 2010; Xiang et al. 2013). The evolution of the WNPSH may be hard to capture with a domain-fitted index ( $\mathrm{Lu}$ 2002). The SAH, in contrast, is mainly a passive response to heating in the Asian monsoon region (e.g., Duan and Wu 2005; Liu et al. 2001; Qian et al. 2002; Reiter and Gao 1982), and its intensification is suggested to be greatly affected by Indian Ocean warming $(\mathrm{Qu}$ and Huang 2012). The domain of the SAH index can basically cover the core region of the SAH, which may contribute to the high correlation between the SAH index and HTEs.

In recent decades, teleconnections of ENSO with the Indo-Pacific have strengthened due to intensified and 

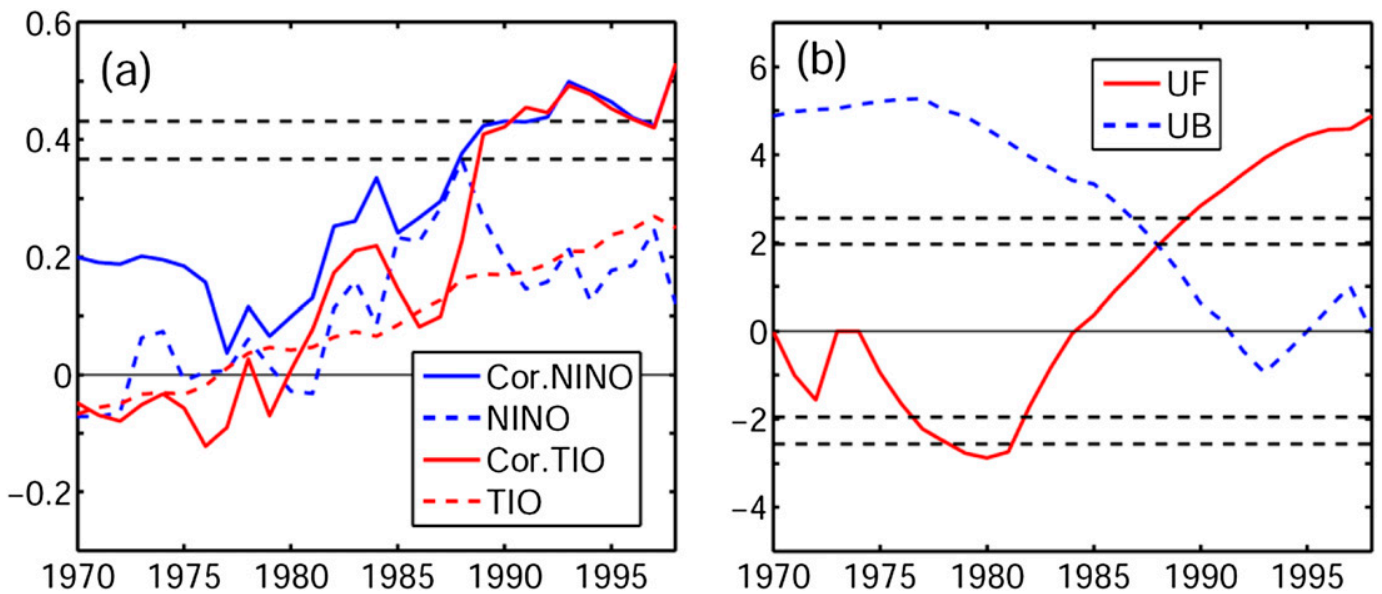

FIG. 4. (a) Dashed curves: 21-yr running mean of normalized DJF(0) Niño-3.4 (blue) and MAM(1) TIO (red) index; solid curves: 21-yr running correlation of PC1 of JA(1) HTEs with DJF(0) Niño-3.4 (blue) and MAM(1) TIO (red) index. The dashed horizontal lines denote the $90 \%$ and the $95 \%$ confidence level when total degrees of freedom are estimated at 19. (b) Mann-Kendall test for 21-yr running correlation between PC1 of HTEs and Niño-3.4 index [the solid blue line in (a)]. UF is the series of the Mann-Kendall test statistic. UB is the inverse series of the Mann-Kendall test statistic. The dashed horizontal lines represent the $95 \%$ and $99.9 \%$ confidence levels of the Mann-Kendall test.

persistent ENSO activities (McGregor et al. 2013). These teleconnections, including persistent TIO warming and an enhanced SAH and WNPSH, are found to be linked with HTEs in southeast China (Figs. 4a and 6b). In the summer following the mature phase of El Niño, increasing precipitation over the Indian Ocean basin due to ocean warming forces a Matsuno-Gill pattern (Matsuno 1966; Gill 1980) in the troposphere. This causes tropospheric temperatures to increase and a baroclinic Kelvin wave to emanate into the western Pacific, inducing northeasterly surface wind anomalies, triggering an anomalous anticyclone in the WNP (Xie et al. 2010), and resulting in surface warming in South China (Hu et al. 2011). Wu et al. (2009, 2010) found that contributions of the Indian Ocean and local SSTs in the WNP to the maintenance of the WNPSH are seasonally dependent: the negative SSTA in the WNP is crucial in early summer, whereas the Indian Ocean plays a crucial role in late summer via anticyclonic shear and boundary layer divergence induced by a Kelvin wave. The ENSOEASM coupled climate shift occurred in the late 1970s. Correlations of HTEs in southeast China with TIO warming and extended atmospheric systems have continued to rise in recent decades, and a significant abrupt shift is found in the late 1980s. Hu et al. (2013) suggested that this is induced by circulation changes in East Asia due to changes in the location of warming in the Indian Ocean, with a focus on HTEs in the southern Yangtze River valley. In section $3 c$, we will propose an explanation for the response of circulation anomalies to the first two leading EOF patterns of HTEs in southeast China (Fig. 2), while in section $3 b$ we will first clarify the association of PC1 in the POST epoch with the ENSO cycle.

\section{b. Association with the ENSO cycle}

The wavelet power spectrum of PC1 in Fig. 3a suggests a prominent quasi-biennial signal in the HTEs of southeast China. This quasi-biennial variation suggests that HTEs in southeast China are associated with the tropospheric biennial oscillation (TBO), which is a wellknown phenomenon in the Asian-Australian monsoon system (Lau and Sheu 1988; Li et al. 2001; C. Li et al. 2011; Meehl 1987; Meehl et al. 2003). The TBO is more likely a tendency for the system to flip-flop back and forth from year to year, that is, for a relatively strong monsoon to be followed by a relatively weak one, and vice versa (Meehl and Arblaster 2002). This biennial tendency is a fundamental time scale involved in the ENSO-monsoon interaction (Chang and Li 2000; Meehl 1997; Shen and Lau 1995; Kim and Lau 2001; Zhou et al. 2008). A spectrum peak at 2-3 years implies bonding of HTEs with the ENSO-monsoon coupling system.

To clearly elucidate the interannual variability of HTEs associated with the ENSO cycle, the ENSOdeveloping year is designated as year 0 and the ENSOdecaying year is designated as year 1 for convenience. Correlations of JA(1) HTEs with Pacific and Indian Ocean SSTAs in 1988-2008 (i.e., the POST epoch) are given in Figs. 5a-e. The domains of Niño-3.4 and TIO are denoted in red boxes. Seasonal correlations evolve between the equatorial Pacific and the TIO. Significant correlated SSTAs over the equatorial central Pacific start to appear in the preceding summer (Fig. 5a). These 
(a) $\operatorname{JJA}(0)$

(f) $\operatorname{JJA}(0)$
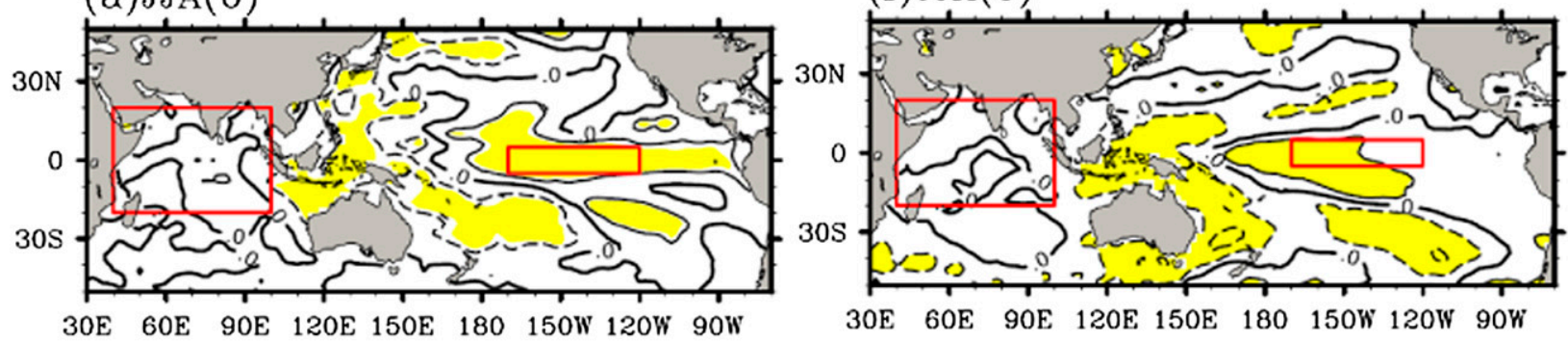

(b) $\operatorname{SON}(0)$

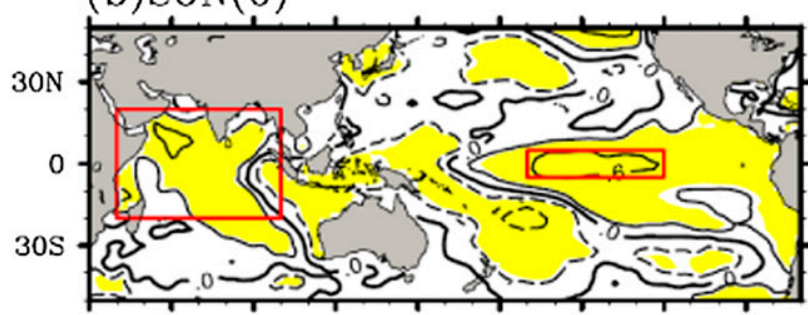

$30 \mathrm{E} 60 \mathrm{E}$ 90E $120 \mathrm{E} \quad 150 \mathrm{E} \quad 180$ 150W 120W 90W

$(\mathrm{g}) \operatorname{SON}(0)$

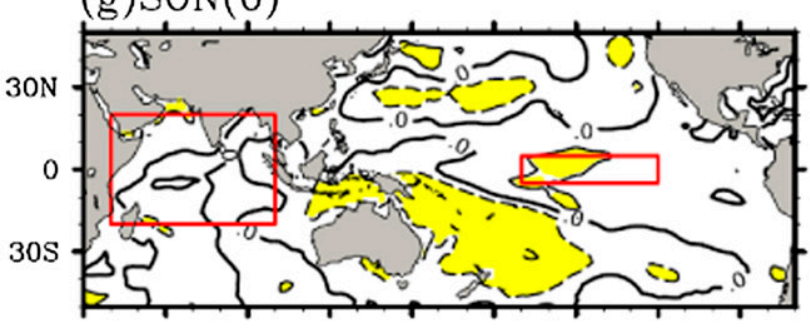

$30 \mathrm{E} \quad 60 \mathrm{E} \quad 90 \mathrm{E} \quad 120 \mathrm{E} \quad 150 \mathrm{E} \quad 180 \quad 150 \mathrm{~W} \quad 120 \mathrm{~W} 90 \mathrm{~W}$

(c) $\operatorname{DJF}(0)$

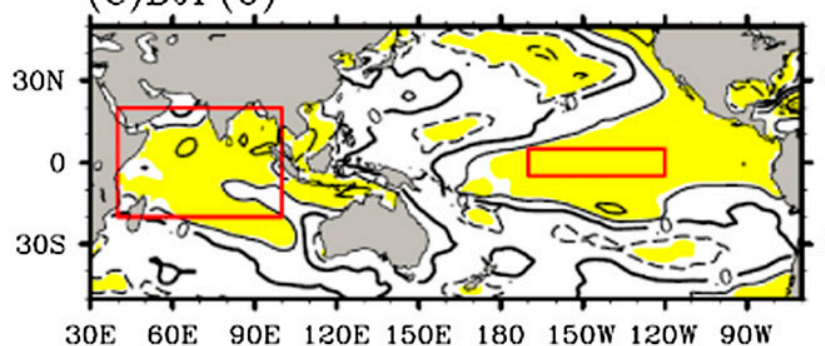

30E $60 \mathrm{E}$ 90E $120 \mathrm{E} \quad 150 \mathrm{E} \quad 180$ 150W 120W 90W

(h) DJF(0)

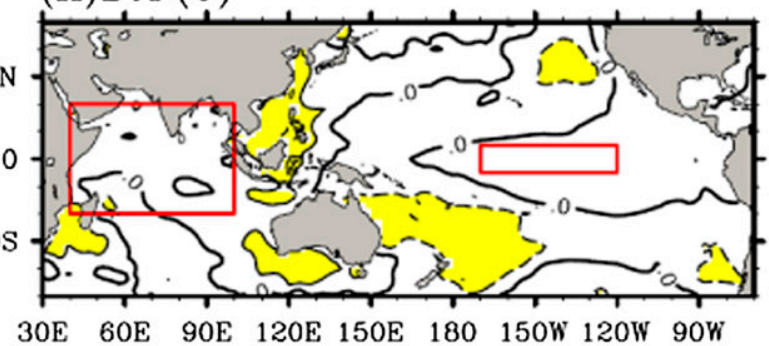

(d) $\operatorname{MAM}(1)$

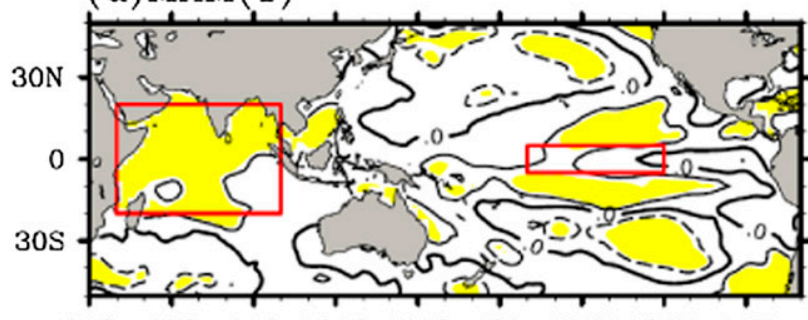

(i) $\operatorname{MAM}(1)$

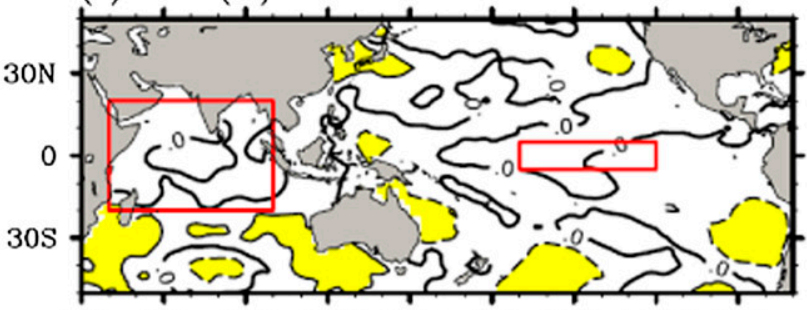

$30 \mathrm{E} \quad 60 \mathrm{E} \quad 90 \mathrm{E} \quad 120 \mathrm{E} \quad 150 \mathrm{E} \quad 180 \quad 150 \mathrm{~W}$ 120W $90 \mathrm{~W}$

30E $60 \mathrm{E}$ 90E 120E 150E 180 150W 120W 90W

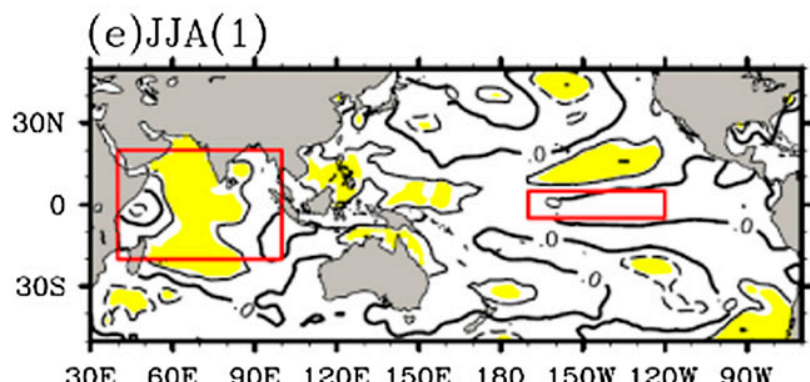

(j)JJA(1)

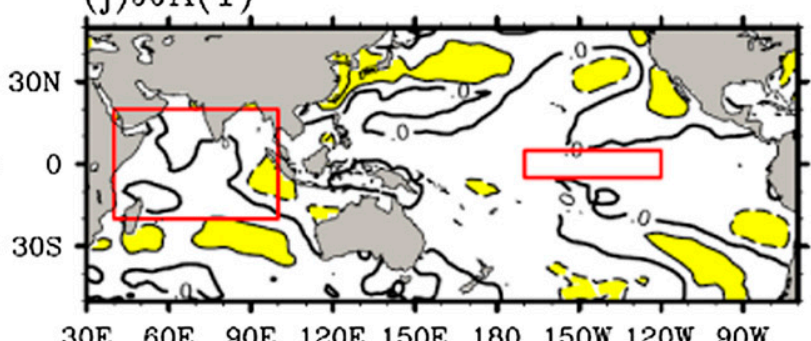

FIG. 5. Seasonal march correlation of SSTAs with PC1 of JA(1) HTE in the (a)-(e) POST and (f)-(j) PRE epochs. Shading donates areas in which correlation coefficients are statistically significant at the $90 \%$ confidence level. Red boxes denote domains of Niño-3.4 and TIO. 

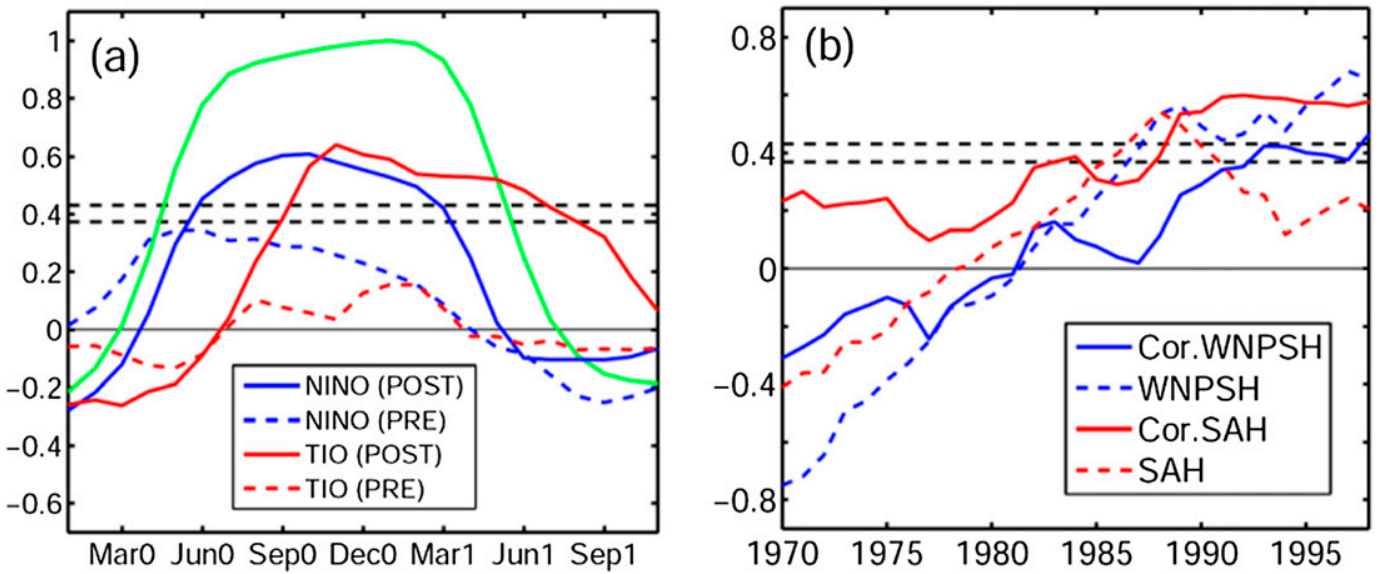

FIG. 6. (a) Correlations of PC1 of HTEs with the Niño-3.4 (blue) and TIO (red) indices in the POST (solid) and PRE (dashed) epochs. The green line represents autocorrelations of the DJF(0) Niño-3.4 index with Niño-3.4 SSTAs. The dashed horizontal line denotes the $95 \%$ confidence level when total degrees of freedom are estimated at 19 for the POST epoch and 26 for the PRE epoch. (b) As in Fig. 4a, but for JA(1) WNPSH and SAH.

signals extend in the equatorial eastern Pacific in September-November $(\mathrm{SON})(0)$ and appear in the western Indian Ocean. Meanwhile, negative correlations occur in the western Pacific and the eastern Indian Ocean (Fig. 5b). In the mature phase of El Niño [i.e., DJF(0)], significant correlations reach peak domains in both the eastern Pacific and the basin of the Indian Ocean (Fig. 5c). Generally, negative SSTAs over the Indo-Pacific region appear to be associated with positive SSTAs in the equatorial eastern Pacific in the developing summer of El Niño. Positive SSTAs show up in the western TIO in $\operatorname{SON}(0)$, while the eastern TIO still has negative SSTAs. This is likely to induce an Indian Ocean dipole (IOD) event (Saji et al. 1999). The whole Indian Ocean basin warms up when El Niño reaches its peak in DJF (0), which may be referred to as the Indian Ocean basin mode (IOBM) (e.g., Klein et al. 1999). Furthermore, impacts of ENSO persist until the following spring through Indian Ocean warming. Correlations remain above the $90 \%$ significance level in the TIO in MAM (1). The warmer Indian Ocean and cooler WNP with a normal El Niño event are not so evident in JJA(1), as declared by $\mathrm{Wu}$ et al. (2009). This may be due to the seasonally dependent contributions of the Indian Ocean and local SSTs in the WNP, as suggested by Wu et al. (2010).

Figure 5 basically shows how the HTEs in southeast China follow an ENSO cycle associated with the Indian Ocean. Figure $6 \mathrm{a}$ further elucidates these couplings by showing correlations of HTEs with the Niño-3.4 and TIO indices in seasonal cycles. The green line in Fig. 6a describes autocorrelations of the $\operatorname{DJF}(0)$ Niño-3.4 index with Niño-3.4 SSTAs. It approximately represents an ENSO cycle and its mature phase in boreal winter. The dashed horizontal line denotes the $95 \%$ confidence level when the total degrees of freedom are estimated at 19 for the POST epoch and 26 for the PRE epoch. In the POST epoch, the correlation with the Niño-3.4 index (blue solid line) in the preceding January-March is below 0 , and it increases with the development of El Niño, goes above the $95 \%$ confidence level from the preceding June to the following February, and reaches its peak value of 0.61 in October of year 0 . The correlation with the TIO (red solid line) displays a "phase displacement" compared to the Niño-3.4 index; it is significant from the preceding September to the following August, reaching its peak value of 0.64 in November of year 0 .

Correlations of the Niño-3.4 index and HTEs in China in the POST epoch are shown in Fig. 7. Figure 7a shows correlations of the $\operatorname{DJF}(0)$ Niño-3.4 index and JA(0) HTEs, while Fig. $7 \mathrm{~b}$ shows correlations of the $\operatorname{DJF}(0)$ Niño-3.4 index and JA(1) HTEs. A prominent phenomenon is that large areas of significant positive correlations in northern and western China are found in Fig. 7a, while large areas of significant negative correlations in western and northeastern China are found in Fig. 7b. This implies that summertime HTEs in northern regions of China follow a warming-cooling phase of ENSO. It is noteworthy that the polarities of correlation coefficients in southeast China are the opposite of those in the northern regions. Negative correlations between the $\operatorname{DJF}(0)$ Niño-3.4 index and JA(0) HTEs are found in the southeastern region but are mainly nonsignificant (Fig. 7a), while significant positive correlations between the DJF(0) Niño-3.4 index and JA(1) HTEs are found in this region (Fig. 7b). In northern China, particularly in the northeastern regions, HTEs are below normal. Previous studies (e.g., Hu et al. 2012) have suggested 
(a) DJF(0) Nino-3.4 cor. JA(0) HTE

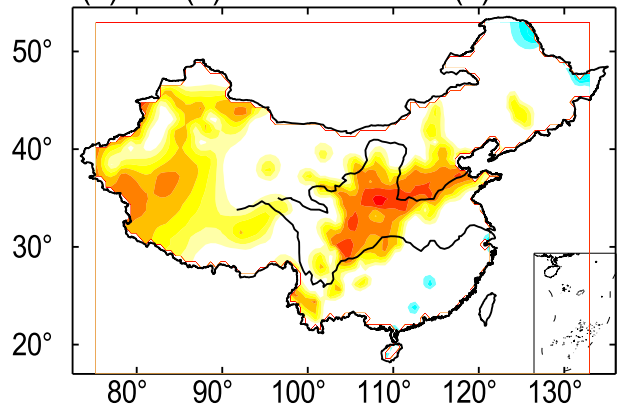

(b) DJF(0) Nino-3.4 cor. JA(1) HTE

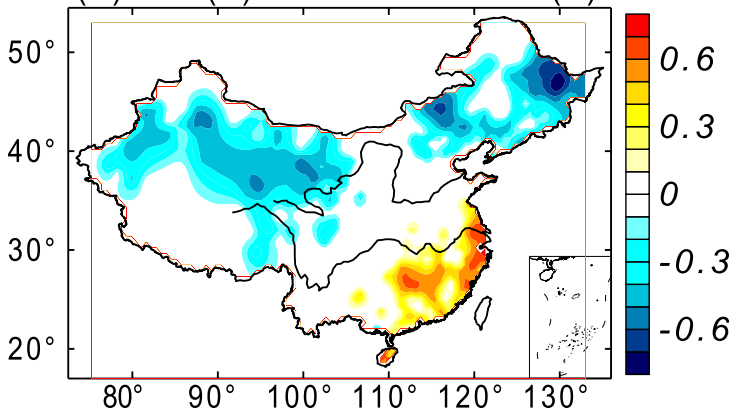

FIG. 7. Correlations of the Niño-3.4 index and HTEs in China in the POST epoch. (a) Correlations of DJF(0) Niño3.4 and JA(0) HTEs. (b) Correlations of DJF(0) Niño-3.4 and JA(1) HTEs. Only correlations above the $90 \%$ confidence level in an $r$ test are plotted. The small insert panel shows the South China Sea.

that this seesaw pattern of the near-surface temperature in south and northeast China is linked with ENSO through the East Asia-Pacific (Huang and Lu 1989) and Pacific-Japan (Nitta 1987) meridional wave train. Variations of HTEs in northern China are not within the scope of this study. We focus on JA(1) HTEs in southeast China, which are significantly correlated with the DJF(0) Niño-3.4 index as shown in Fig. 7b. More importantly, linkages with the preceding ENSO signal are meaningful for the predictability of summer HTEs. The next section investigates how HTEs in southeast China are associated with simultaneous atmospheric circulation anomalies in the EASM system. The spatial differences in the region are considered; that is, both the $\mathrm{PC} 1$ and PC2 of HTEs in southeast China are taken into account in the investigation.

\section{c. Coupling in the EASM system}

Correlation of PC2 with the area-averaged time series (Fig. 1c) in 1960-2008 is only 0.08, as mentioned above. However, the correlation of $\mathrm{PC} 2$ with the area-averaged time series is -0.50 (at the $95 \%$ confidence level) and 0.42 (at the $90 \%$ confidence level) in the PRE and POST epochs, respectively, which implies that EOF2 is related to the interdecadal change. To investigate HTEs in relation to EASM systems, we use $200-\mathrm{hPa}$ zonal wind, 150-hPa geopotential height, and 500-hPa geopotential height to represent the EAJS, the SAH, and the WNPSH, respectively. The interdecadal change revealed in the previous section is taken into consideration. The following linear correlations between the first two leading PCs and atmospheric parameters are calculated separately for the two epochs (Figs. 8-10).

Figure 8 shows that in the PRE epoch, both PC1 and PC2 are highly correlated with 200-hPa zonal wind speed anomalies in East Asia. The climatological axis of the EAJS is located at around $40^{\circ} \mathrm{N}$. In Fig. 8 a, positive (negative) zonal wind speed anomalies are found to the north (south) of the jet axis, implying a northward displacement of the EAJS (e.g., Zhang et al. 2006). Poleward displacement of the EAJS is linked to surface warming in eastern China. The situation in Fig. $8 \mathrm{c}$ is the opposite, as PC2 has a significant negative correlation of -0.50 with PC1 in the PRE epoch, but the small magnitude of PC2 compared to PC1 in the PRE epoch (Fig. 2) suggests this southward displacement of the EAJS is insignificant to the change in HTEs in southeast China. Associated with the displacement of the westerly jet in the tropopause, geopotential height anomalies occur in the lower stratosphere and the upper troposphere. This is evident in Figs. 9 and 10. A belt of positive (negative) anomalies along $40^{\circ} \mathrm{N}$ is found in the $150-\mathrm{hPa}$ geopotential height associated with the northward (southward) displacement of the EAJS in Fig. 9a (Fig. 9c). In the middle levels of the troposphere, the association of geopotential height anomalies becomes weaker compared to upper levels, and the anticyclonic (cyclonic) anomaly center over the Bohai Bay-Korean Peninsula is correlated with PC1 (PC2), as shown in Fig. 10a (Fig. 10c). But again, we argue that circulation anomalies associated with PC2 in the PRE epoch are insignificant to the change in HTEs in southeast China because they are much smaller in magnitude than those associated with PC1.

In the POST epoch, the northward displacement of the EAJS associated with PC1 weakens (Fig. 8b) compared to that in the PRE epoch. Geopotential height anomalies at $150-\mathrm{hPa}$ shift mainly to low-latitude regions, with one located around $30^{\circ} \mathrm{N}$ and another in the tropics (Fig. 9b). PC2 links with a coupled troughridge system (Fig. 8d): weakening zonal wind to the south of $30^{\circ} \mathrm{N}$ associated with southward displacement of the EAJS implies an enhancement of the SAH, as can be seen in Fig. 9d. In the middle level of $500 \mathrm{hPa}$, positive geopotential height anomalies cover the WNP and southern Asia in association with PC1 and PC2 

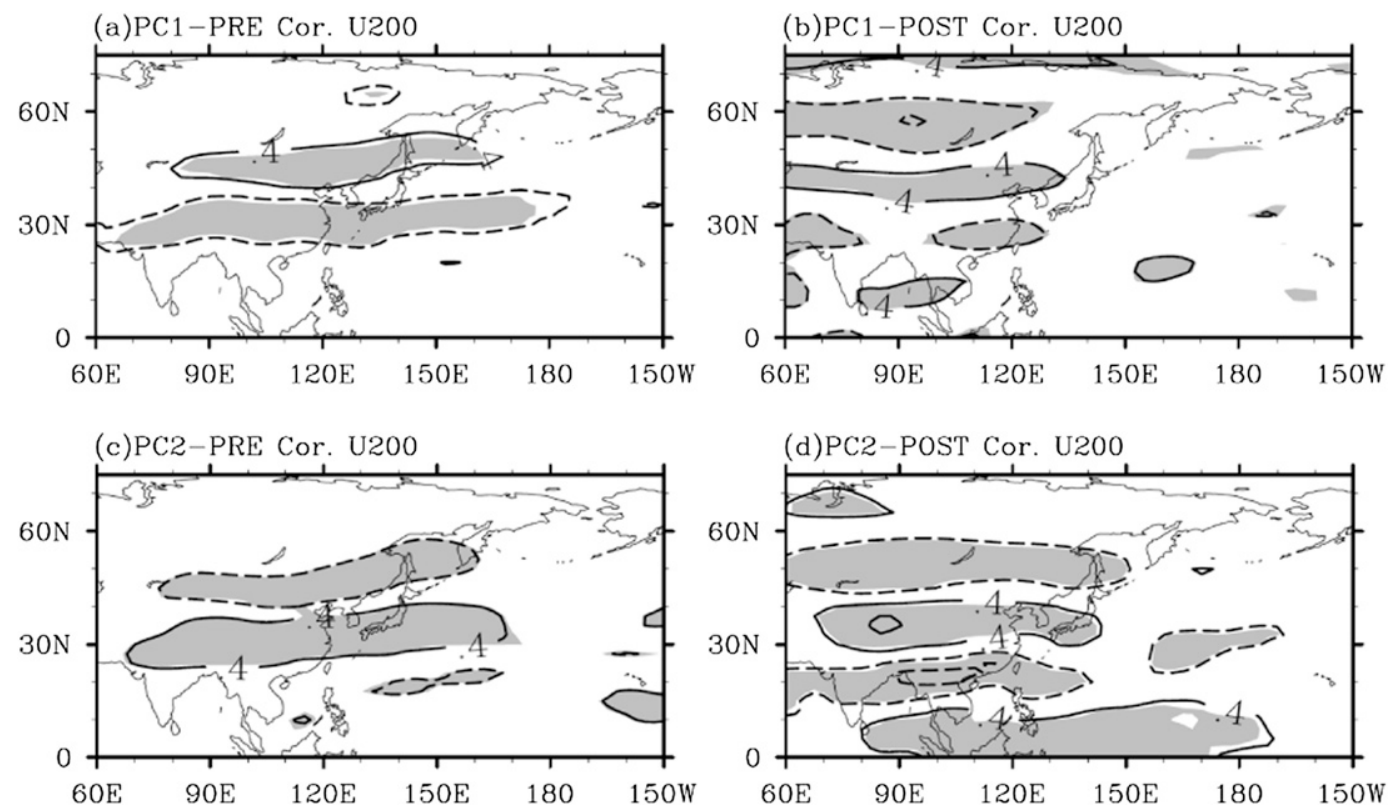

FIG. 8. Correlation of the first two leading PCs of HTEs with 200-hPa zonal wind in the (a),(c) PRE and (b),(d) POST epochs, respectively. Shading denotes significant correlations at the $95 \%$ confidence level in the $r$ test.

(Figs. 10b,d). This kind of anomaly implies a southwestward extension of the WNPSH (Zhou and Yu 2005). However, positive geopotential height anomalies associated with PC1 cover southern China and extend northward up to nearly $40^{\circ} \mathrm{N}$, while there are negative anomalies to the north of $30^{\circ} \mathrm{N}$ associated with PC2.
The EOF analysis decomposes the signal in terms of orthogonally based functions that are determined from observational data, and both spatial patterns and time series can be obtained. In a specific year, whether a selected EOF pattern is dominant or not is important to a physical explanation. Composite analysis is needed in some cases to further validate the result of correlation
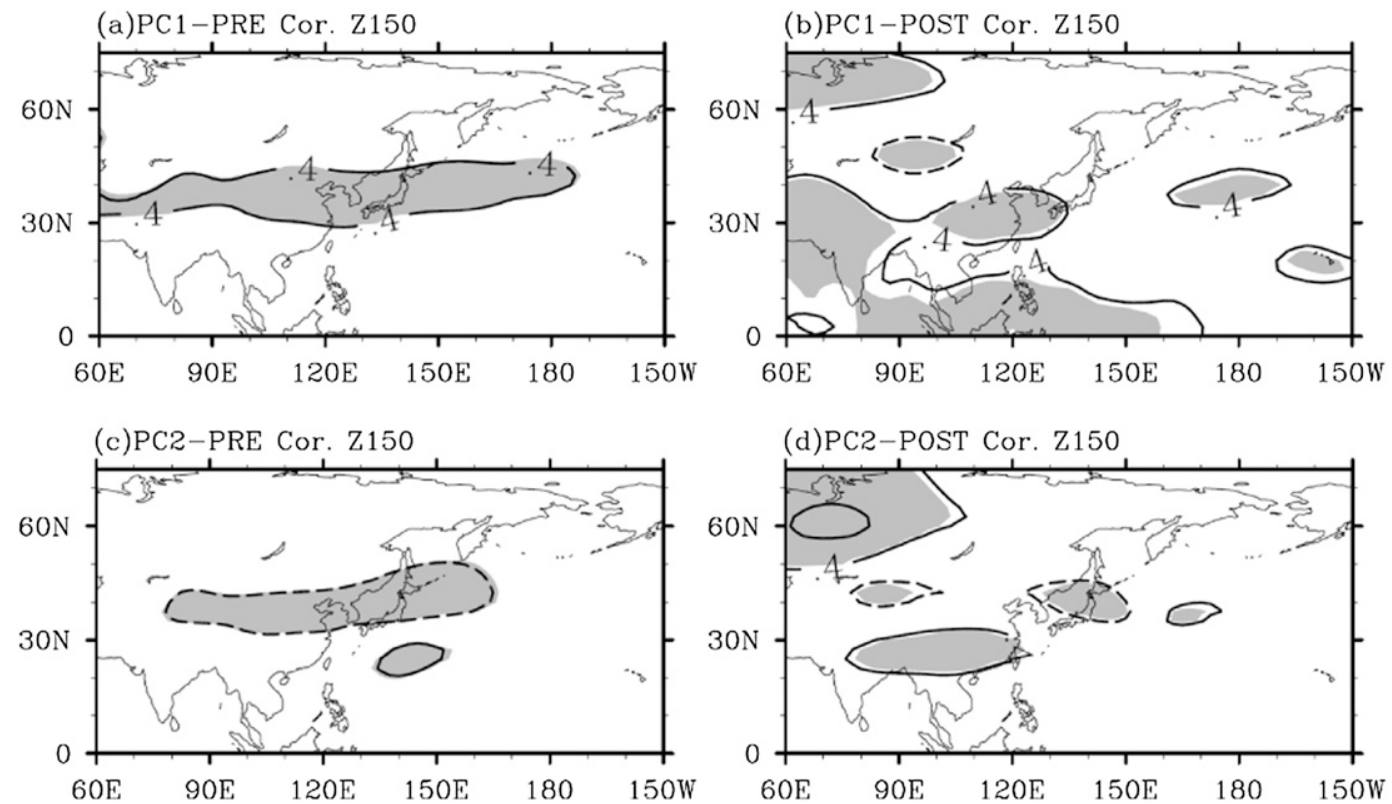

FIG. 9. As in Fig. 8, but for 150-hPa geopotential height. 

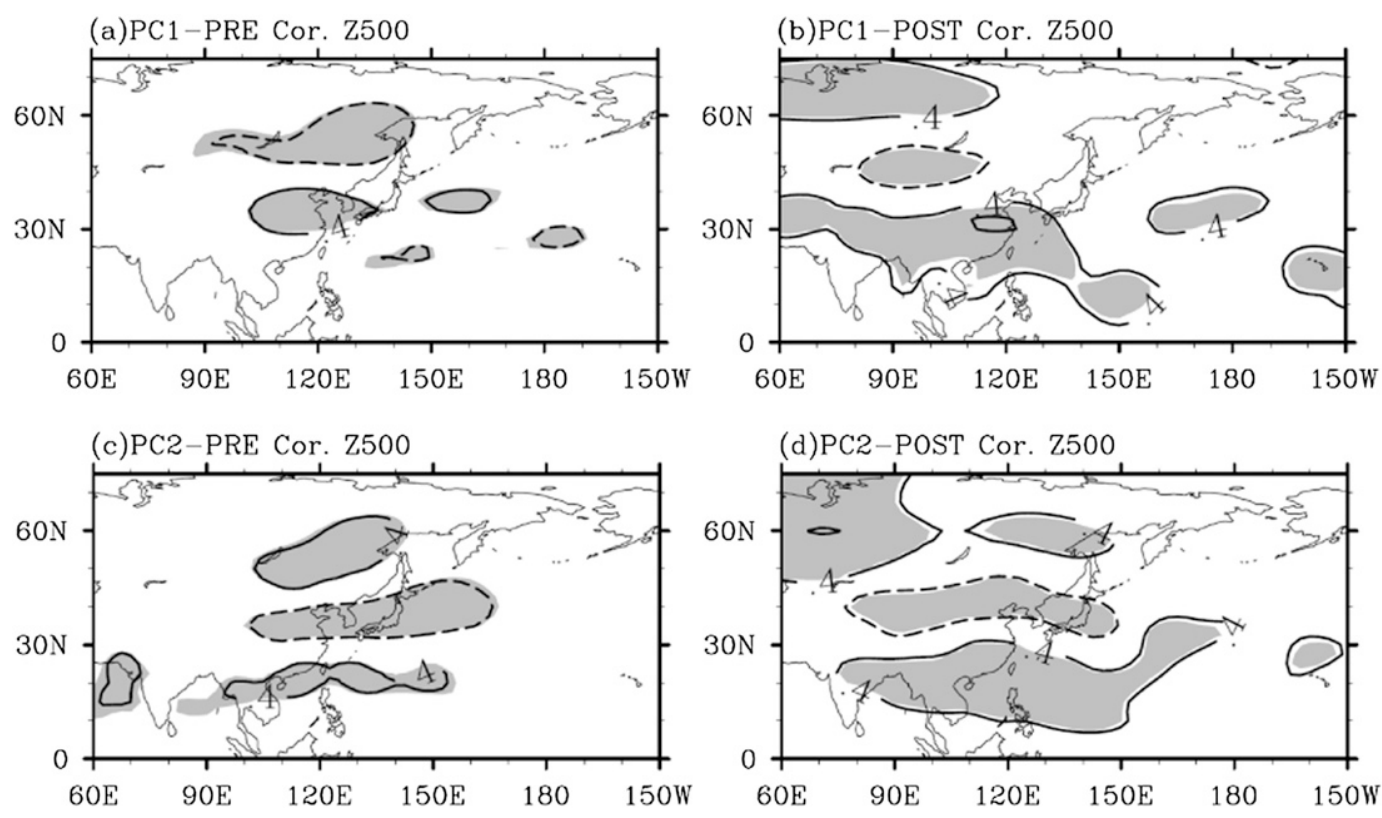

FIG. 10. As in Fig. 8, but for 500-hPa geopotential height.

analysis. In this process, the first 10 leading EOFs are extracted. In each summer, one dominant EOF mode stands out that contains the largest value among the 10 PCs of all 10 leading EOFs in that summer. Table 1 shows that 28 out of 49 summers demonstrate dominance in the first two leading EOF modes. These 28 summers are further divided into four groups based on the polarity of the dominant mode, including 9 years of positive EOF1, 12 years of negative EOF1, 2 years of positive EOF2, and 5 years of negative EOF2. It is noteworthy that there is only one dominant year (1985) of EOF2 in the PRE epoch, indicating that EOF2 demonstrates dominance mainly after the interdecadal climate shift. Finally, the composition is conducted by summers with the positive mode demonstrating dominance minus summers with the negative mode demonstrating dominance. Composite 200-hPa zonal wind and 150- and 500-hPa geopotential height for the summers demonstrating dominance in EOF1 and EOF2 are given in Fig. 11.

Composite results of 200-hPa zonal wind agree well with the correlations. The significant difference in $200-\mathrm{hPa}$ zonal wind between the positive and negative mode of EOF1 (EOF2) suggests a poleward (equatorward) displacement of the EAJS, as shown in Fig. 11a (Fig. 11b). The equatorward displacement of the EAJS associated with the EOF2 pattern also induces a coupled trough-ridge system in the low latitudes, just as in the correlation results of PC2 in the POST epoch. Anticyclonic $150-\mathrm{hPa}$ geopotential height anomalies over Eurasia and the Pacific are connected with the dominant phase of EOF1 (significant differences between summers when the positive and negative modes are dominant), as shown in Fig. 11c. Along with the waveguide of the westerly jet, the circumglobal teleconnection (CGT) pattern has long been realized (e.g., Ding and Wang 2005). Figure 11c shows the linkage between HTEs in southeast China and the CGT pattern in the lower level of the stratosphere $(150 \mathrm{hPa})$. Only linkages with the East Asia-Pacific sectors are shown here, while linkages with all five sectors in the Northern Hemisphere can be found in our previous study (W. Wang et al. 2013b). These connections with geopotential height anomalies weaken in the middle level $(500 \mathrm{hPa})$ of the troposphere

TABLE 1. List of years for the period of 1960-2008 showing dominance in the first leading EOF modes.

\begin{tabular}{lcl}
\hline \hline EOF modes & No. of years & \multicolumn{1}{c}{ Dominant years } \\
\hline EOF1+ & 9 & $1961,1966,1967,1971,1978,1988,1990,1994$, and 2003 \\
EOF1 - & 12 & $1960,1965,1968,1969,1970,1974,1975,1982,1987,1993,1999$, and 2008 \\
EOF2+ & 2 & 1998 and 2007 \\
EOF2- & 5 & $1985,1997,2001,2002$, and 2006 \\
\hline
\end{tabular}


(a) Com. U200 (EOF1)

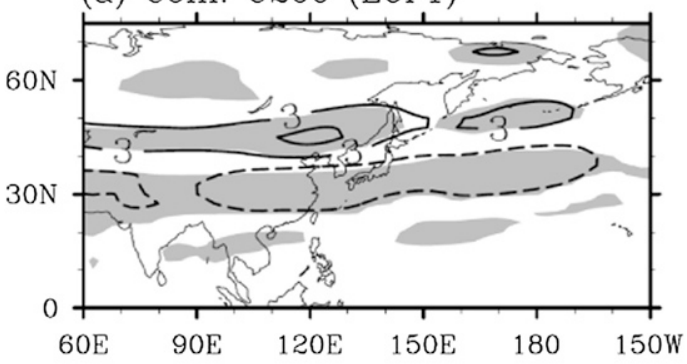

(c) Com. Z150 (EOF1)
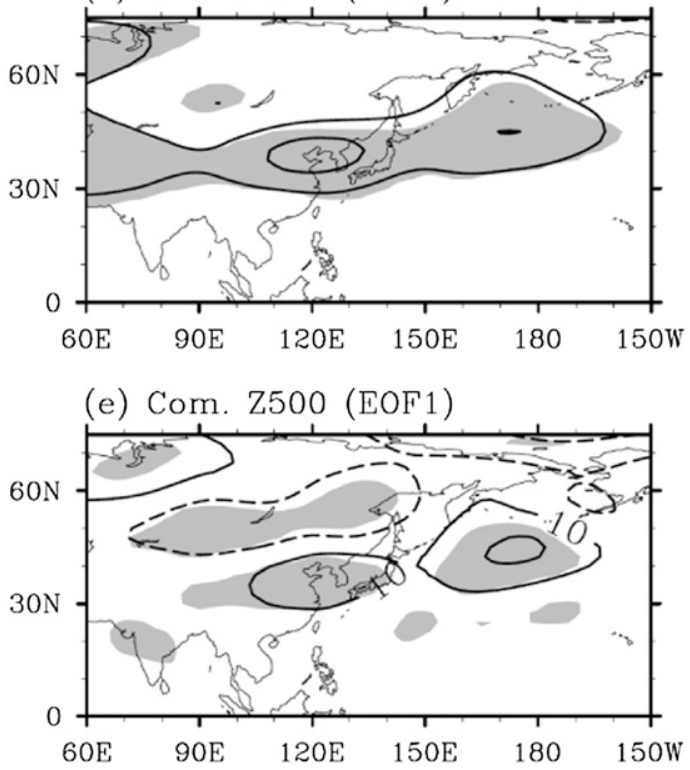

(b) Com. U200 (EOF2)

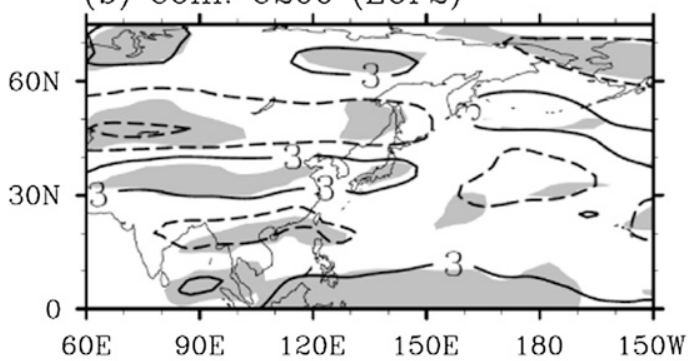

(d) Com. Z150 (EOF2)
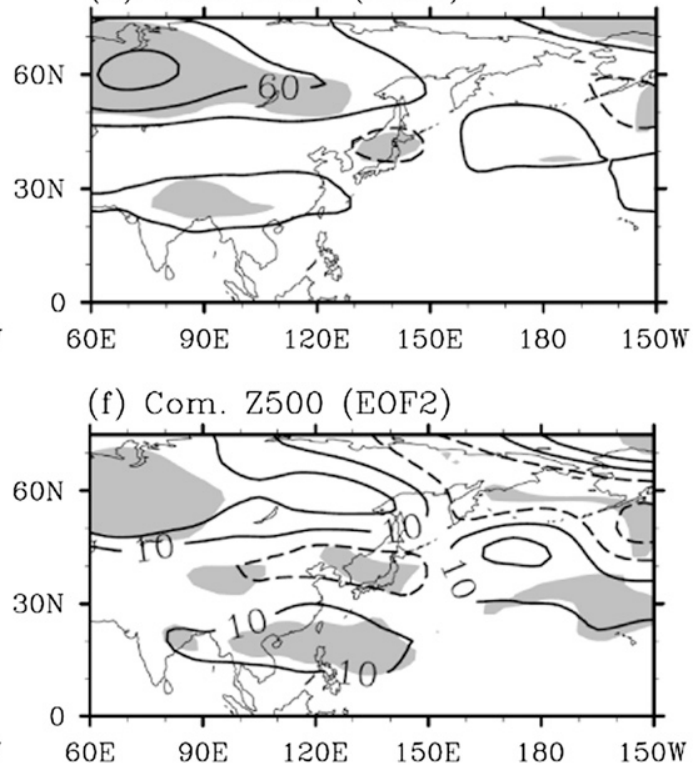

FIG. 11. Composite (a),(b) 200-hPa zonal wind ( $\mathrm{m} \mathrm{s}^{-1}$ ); (c),(d) 150-hPa geopotential height (m); and (e),(f) 500-hPa geopotential height $(\mathrm{m})$ for the summers demonstrating dominance in (left) EOF1 and (right) EOF2. Shading indicates regions that are significantly different in two polarities at the $90 \%$ confidence level in the Student's $t$ test.

(Fig. 11e). Only regions localized in East Asia and the northern Pacific are retained. Composite results of 150and $500-\mathrm{hPa}$ geopotential height for EOF2 are also consistent with the correlations, as shown in Figs. 11d and 11f. Evidence can be found to support the increasing effects of the SAH and WNSPH on EOF2. Corresponding to the 200-hPa zonal wind anomalies in Fig. $11 \mathrm{~b}$, that is, westerly anomalies to the north and easterly anomalies to the south of $30^{\circ} \mathrm{N}$, positive $150-\mathrm{hPa}$ geopotential height anomalies occur in the $\mathrm{SAH}$ region (Fig. 11b). The positive 500-hPa geopotential height anomalies in the WNP and northern South China Sea in Fig. 11f suggest a southwestward extension of the WNPSH (Zhou and Yu 2005). To the north of around $30^{\circ} \mathrm{N}$, negative anomalies of 500-hPa geopotential height are found, which agrees with correlation results and also the positive phase of EOF2.

In general, linear correlation has not taken the dominance of EOFs into consideration, while composite analysis may include more uncertainty due to the limited sample (e.g., only 2 years and 5 years of the positive and negative phases of EOF2 showing dominance, respectively, as listed in Table 1). We conduct both correlation and composite analysis to double-check the circulation anomalies associated with HTE variations. Based on this investigation, we summarize our findings and propose a possible mechanism for the coupled effects of the EAJS, SAH, and WNPSH on summer HTEs in southeast China in the schematics shown in Fig. 12.

An interdecadal change in HTEs in southeast China associated with the abrupt regime shift of the ENSOmonsoon climate system in the late 1980s is apparent. Before this shift, temperature adjustments associated with the meridional displacement of the EAJS were the main factor in HTE anomalies. Poleward displacement of the EAJS [i.e., westerly (easterly) anomalies to the north (south) of the climatological axis of the jet around $\left.40^{\circ} \mathrm{N}\right]$ results in anticyclonic geopotential height anomalies 

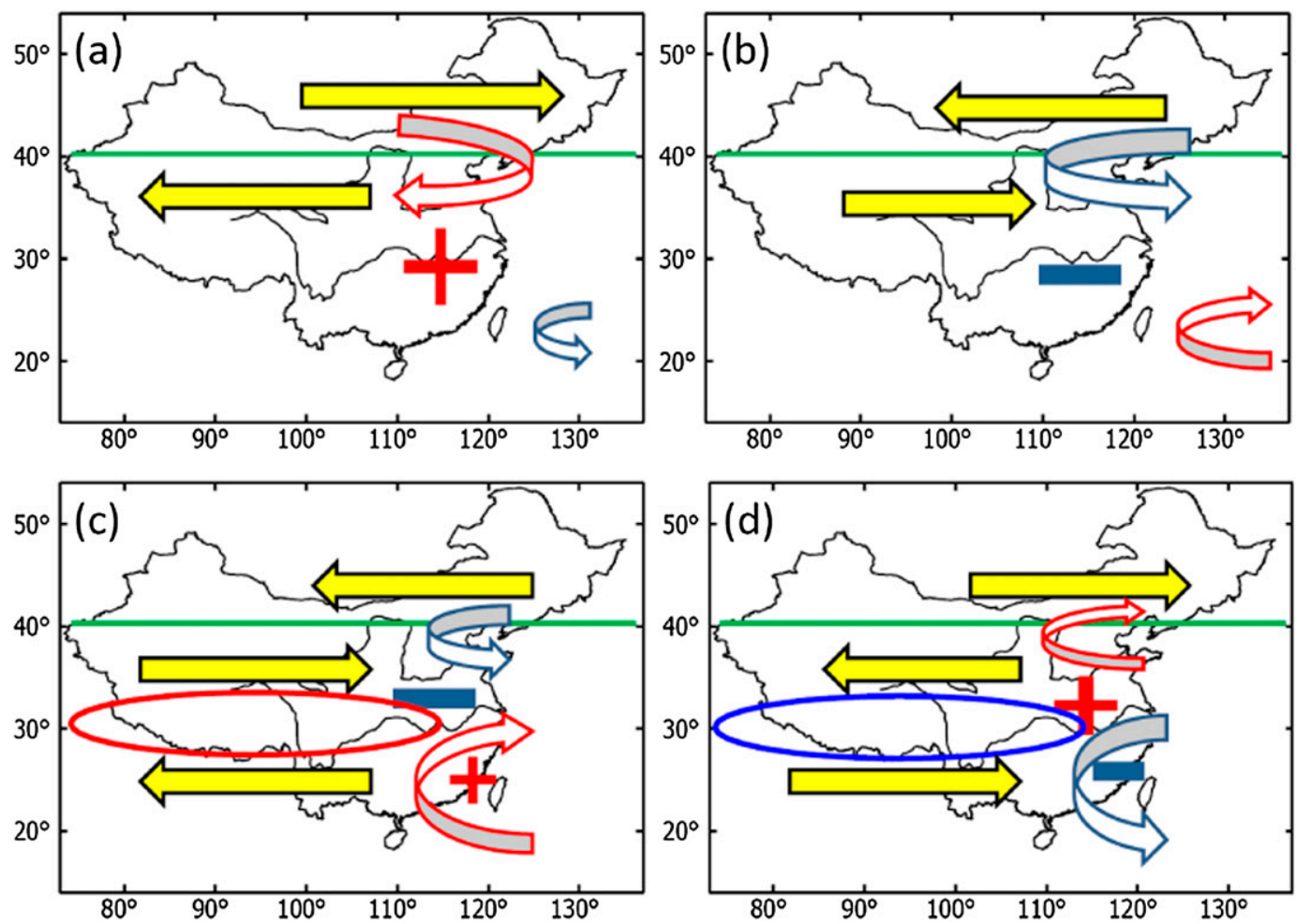

FIG. 12. Schematics showing the coupled dynamics of atmospheric systems in the EASM and their impacts on HTEs in southeast China. Green lines denote the climatological location of the EAJS. Yellow arrows denote zonal wind speed anomalies. Red (blue) curved arrows denote anticyclonic (cyclonic) geopotential height anomalies. Red (blue) ellipse denotes strengthening (weakening) of the SAH. Plus (minus) symbols denote increasing (decreasing) change in HTEs. (a) Strong poleward displacement of the EAJS, denoted as westerly (easterly) anomalies to the north (south) of the jet axis, results in strong anticyclonic geopotential height anomalies in the midlatitudes of East Asia and is responsible for the positive phase of EOF1 of HTEs in southeast China. (b) Atmospheric anomalies of the opposite situation to that of (a) are responsible for the negative phase of EOF1 of HTEs in southeast China. (c) Southward displacement of the EAJS associated with enhancement of the SAH and the WNPSH, and cyclonic (anticyclonic) geopotential height anomalies in the east-central (southeast) region, are responsible for the positive phase of EOF2 of HTEs. (d) Atmospheric anomalies of the opposite situation to that of (c) are responsible for the negative phase of EOF2 of HTEs.

being maintained over east-central China that are associated with positive anomalies in HTEs in southeast China (Fig. 12a), and vice versa (Fig. 12b). After the interdecadal shift, teleconnections of ENSO with the Indo-Pacific strengthened due to intensified and persistent ENSO activities. These teleconnections, including persistent TIO warming and enhanced SAH and WNPSH, are found to be linked with HTEs in southeast China. The situation shown in Figs. 12a and 12b may still dominate in some years (e.g., years showing dominance in EOF1 listed in Table 1). The coupling effects of the three circulation components of the EASM are dominant in other cases. In these cases, the EAJS moves equatorward and results in a sandwich-like structure of zonal wind anomalies in the upper levels, as shown in Fig. 12c. Cyclonic geopotential height anomalies localize over east-central China. Intensified SAH and WNPSH are associated with positive SSTAs in the TIO. These combined effects contribute to a positive phase in the EOF2 spatial pattern of southeast China HTEs. In the same way, the negative phases of the HTE EOF2 pattern are contributed by opposite coupled circulation patterns (Fig. 12d).

\section{Conclusions and discussion}

Under the background of global warming, more attention should be paid to summer HTEs and their increasing impact on the natural environment and human society. It is important to gain a better understanding of the underlying mechanism of how HTEs are linked to atmospheric anomalies in the changing climate. This study focuses on interannual variability of summer (JulyAugust) HTEs in a study domain in southeast China, 
enclosed by the box in Fig. 1a. EOF analysis is first applied to characterize the temporal and spatial pattern of HTEs. Only the first two leading modes are well separated from the other modes (North et al. 1982). EOF1 exhibits a uniform spatial pattern with a maximum variance center over the lower Yangtze River valley, while EOF2 shows an opposite southeast-northwest pattern. Based on a Mann-Kendall test applied to the running correlation of $\mathrm{PC1}$ of HTEs and the ENSO index, an interdecadal change in $1987 / 88$ is then identified. It is found that after this interdecadal shift, HTEs in southeast China are highly correlated with ENSO, which may be due to intensified and persistent ENSO activities, TIO warming, and changes in atmospheric teleconnection (e.g., Hu et al. 2013; Lin et al. 2010). In addition, the association of HTEs with the ENSO cycle in the POST epoch is discussed. Finally, how HTEs in southeast China are associated with atmospheric circulation anomalies in the EASM system is investigated, and a possible coupled mechanism is proposed: before the interdecadal shift, EOF1, which is linked mainly to the meridional displacement of the EAJS as shown in Figs. 12a and 12b, demonstrates dominance. After the interdecadal shift, both EOF1 and EOF2 demonstrate dominance. EOF2 is linked with emphasizing the coupled anomalies of the EAJS, SAH, and WNPSH, as shown in Figs. 12c and 12d.

In the EASM climate, the abrupt regime shift in the late 1970s, with changes in ENSO activities and a strengthened ENSO-EASM relationship, has been well recognized (e.g., An and Wang 2000; Wang et al. 2008). Our results show that the correlations of SSTAs in the equatorial eastern Pacific and TIO with southeast China HTEs in El Niño decaying summers have continued to increase in recent decades (Fig. 4a). Similar increasing linkages with HTEs in the SAH and the WNPSH indices are found (Fig. 6b). The significant abrupt change in the relationship between the ENSO index and southeast China HTEs is found in 1987/88 (Fig. 4b). This may be due to the relocation of SSTAs in the Indian Ocean and the corresponding atmospheric adjustments in East Asia (Hu et al. 2013).

The meridional displacement of the westerly jet is a remarkable signal of temperature advection, and hence a crucial source of temperature extreme variability (e.g., Mahlstein et al. 2012), which supports the high correlation between the EAJS and HTEs in southeast China. Meridional displacements of the EAJS and their association with variations in the SAH and the WNPSH are dominant circulation features in the EASM climate. Equatorward (poleward) displacement of the EAJS tends to be associated with a stronger (weaker) $\mathrm{SAH}$, whereas a stronger (weaker) SAH tends to be accompanied by a stronger (weaker) and more (less) extensive WNPSH (e.g., Wu et al. 2003; Yang and Zhang 2007; Zhang et al. 2005). This previous understanding of the coupling of the EAJS, SAH, and WNPSH in the EASM climate on an interannual time scale agrees with how they bond with HTEs in southeast China as described in this study. On a climatological time scale, correlation between the WNPSH and summer HTEs may not be significant if the WNPSH is not strong enough (He and Gong 2002); this is the situation in the PRE epoch. In the POST epoch, both the intensification and extension of the SAH and WNPSH may be attributed to the observed Indian Ocean warming (Huang et al. 2011; Zhou et al. 2009c).

Acknowledgments. This research is supported by National Nature Science Foundation of China Grants 41375096 and 41175079, and Macao Meteorological and Geophysical Bureau (SMG) project 9231048.

\section{REFERENCES}

Alexander, L. V., and Coauthors, 2006: Global observed changes in daily climate extremes of temperature and precipitation. J. Geophys. Res., 111, D05109, doi:10.1029/2005JD006290.

An, S.-I., and B. Wang, 2000: Interdecadal change of the structure of the ENSO mode and its impact on the ENSO frequency. J. Climate, 13, 2044-2055, doi:10.1175/1520-0442(2000)013<2044: ICOTSO $>2.0 . \mathrm{CO} ; 2$.

Beard, L. R., 1943: Statistical analysis in hydrology. Trans. Amer. Soc. Civ. Eng., 108, 1110-1160.

Chan, J. C. L., and W. Zhou, 2005: PDO, ENSO and the early summer monsoon rainfall over south China. Geophys. Res. Lett., 32, L08810, doi:10.1029/2004GL022015.

Chang, C.-P., and T. Li, 2000: A theory for the tropical tropospheric biennial oscillation. J. Atmos. Sci., 57, 2209-2224, doi:10.1175/ 1520-0469(2000)057<2209:ATFTTT>2.0.CO;2.

Ding, Q., and B. Wang, 2005: Circumglobal teleconnection in the Northern Hemisphere summer. J. Climate, 18, 3483-3505, doi:10.1175/JCLI3473.1.

Ding, T., W. Qian, and Z. Yan, 2010: Changes in hot days and heat waves in China during 1961-2007. Int. J. Climatol., 30, 14521462, doi:10.1002/joc.1989.

Ding, Y., Y. Sun, Z. Wang, Y. Zhu, and Y. Song, 2009: Interdecadal variation of the summer precipitation in China and its association with decreasing Asian summer monsoon. Part II: Possible causes. Int. J. Climatol., 29, 1926-1944, doi:10.1002/ joc. 1759 .

Donat, M. G., and Coauthors, 2013: Updated analyses of temperature and precipitation extreme indices since the beginning of the twentieth century: The HadEX2 dataset. J. Geophys. Res. Atmos., 118, 2098-2118, doi:10.1002/jgrd.50150.

Du, Y., S.-P. Xie, G. Huang, and K. Hu, 2009: Role of air-sea interaction in the long persistence of El Niño-induced north Indian Ocean warming. J. Climate, 22, 2023-2038, doi:10.1175/ 2008JCLI2590.1.

Duan, A. M., and G. Wu, 2005: Role of the Tibetan Plateau thermal forcing in the summer climate patterns over subtropical Asia. Climate Dyn., 24, 793-807, doi:10.1007/s00382-004-0488-8. 
Gill, A. E., 1980: Some simple solutions for heat-induced tropical circulation. Quart. J. Roy. Meteor. Soc., 106, 447-462, doi:10.1002/qj.49710644905.

Gong, D., Y. Pan, and J. Wang, 2004: Changes in extreme daily mean temperatures in summer in eastern China during 1955-2000. Theor. Appl. Climatol., 77, 25-37, doi:10.1007/ s00704-003-0019-2.

He, X., and D. Gong, 2002: Interdecadal change in western Pacific subtropical high and climatic effects. J. Geogr. Sci., 12, 202 209, doi:10.1007/BF02837475.

Hu, K., G. Huang, and R. Huang, 2011: The impact of tropical Indian Ocean variability on summer surface air temperature in China. J. Climate, 24, 5365-5377, doi:10.1175/2011JCLI4152.1.

- — - X. Qu, and R. Huang, 2012: The impact of Indian Ocean variability on high temperature extremes across the southern Yangtze River valley in late summer. Adv. Atmos. Sci., 29, 91-100, doi:10.1007/s00376-011-0209-2.

and R. Wu, 2013: A strengthened influence of ENSO on August high temperature extremes over the southern Yangtze River Valley since the late 1980s. J. Climate, 26, 2205-2221, doi:10.1175/JCLI-D-12-00277.1.

Huang, G., X. Qu, and K. Hu, 2011: The impact of the tropical Indian Ocean on the South Asian high in boreal summer. $A d v$. Atmos. Sci., 28, 421-432, doi:10.1007/s00376-010-9224-y.

Huang, R., and L. Lu, 1989: Numerical simulation of the relationship between the anomaly of subtropical high over East Asia and the convective activities in the western tropical Pacific. Adv. Atmos. Sci., 6, 202-214, doi:10.1007/BF02658016.

Jenkinson, A. F., 1977: The analysis of meteorological and other geophysical extremes. Synoptic Climatology Branch Memo 58, Met Office, $41 \mathrm{pp}$.

Jones, P. D., E. B. Horton, C. K. Folland, M. Hulme, D. E. Parker, and T. A. Basnett, 1999: The use of indices to identify changes in climatic extremes. Climatic Change, 42, 131-149, doi:10.1023/A:1005468316392.

Kalnay, E., and Coauthors, 1996: The NCEP/NCAR 40-Year Reanalysis Project. Bull. Amer. Meteor. Soc., 77, 437-471, doi:10.1175/1520-0477(1996)077<0437:TNYRP>2.0.CO;2.

Kendall, M. G., 1955: Rank Correlation Methods. 2nd ed. Charles Griffin, 196 pp.

Kim, K. M., and K. M. Lau, 2001: Dynamics of monsoon-induced biennial variability in ENSO. Geophys. Res. Lett., 28, 315-318, doi:10.1029/2000GL012465.

Kistler, R., and Coauthors, 2001: The NCEP-NCAR 50-Year Reanalysis: Monthly means CD-ROM and documentation. Bull. Amer. Meteor. Soc., 82, 247-267, doi:10.1175/ 1520-0477(2001)082<0247:TNNYRM >2.3.CO;2.

Klein, S. A., B. J. Soden, and N.-C. Lau, 1999: Remote sea surface temperature variations during ENSO: Evidence for a tropical atmospheric bridge. J. Climate, 12, 917-932, doi:10.1175/ 1520-0442(1999)012<0917:RSSTVD > 2.0.CO;2.

Lau, K.-M., and P. J. Sheu, 1988: Annual cycle, quasi-biennial oscillation, and Southern Oscillation in global precipitation. J. Geophys. Res., 93, 10 975-10 988, doi:10.1029/JD093iD09p10975.

Li, C., J. Pan, and Z. Que, 2011: Variation of the East Asian monsoon and the tropospheric biennial oscillation. Chin. Sci. Bull., 56, 70-75, doi:10.1007/s11434-010-4200-6.

Li, H., A. Dai, T. Zhou, and J. Lu, 2010: Responses of East Asian summer monsoon to historical SST and atmospheric forcing during 1950-2000. Climate Dyn., 34, 501-514, doi:10.1007/ s00382-008-0482-7.

Li, L., B. Wang, and T. Zhou, 2007: Contributions of natural and anthropogenic forcings to the summer cooling over eastern
China: An AGCM study. Geophys. Res. Lett., 34, L18807, doi:10.1029/2007GL030541.

Li, T., C.-W. Tham, and C.-P. Chang, 2001: A coupled air-seamonsoon oscillator for the tropospheric biennial oscillation. J. Climate, 14, 752-764, doi:10.1175/1520-0442(2001)014<0752: ACASMO $>2.0 . \mathrm{CO} ; 2$.

Li, X., and W. Zhou, 2012: Quasi-4-yr coupling between El Niño-Southern Oscillation and water vapor transport over East Asia-WNP. J. Climate, 25, 5879-5891, doi:10.1175/ JCLI-D-11-00433.1.

_ Z Z. Wen, and W. Zhou, 2011: Long-term change in summer water vapor transport over South China in recent decades. J. Meteor. Soc. Japan, 89A, 271-282, doi:10.2151/jmsj.2011-A17.

Li, Z., and Z. Yan, 2009: Homogenized daily mean/maximum/ minimum temperature series for China from 1960-2008. At mos. Oceanic Sci. Lett., 2, 237-243.

$\longrightarrow$, and 2010: Application of multiple analysis of series for homogenization to Beijing daily temperature series (1960-2006). Adv. Atmos. Sci., 27, 777-787, doi:10.1007/ s00376-009-9052-0.

Lin, Z., R. Lu, and W. Zhou, 2010: Change in early-summer meridional teleconnection over the western North Pacific and East Asia around the late 1970s. Int. J. Climatol., 30, 2195 2204, doi:10.1002/joc.2038.

Liu, Y., G. Wu, H. Liu, and P. Liu, 2001: Condensation heating of the Asian summer monsoon and the subtropical anticyclones in the Eastern Hemisphere. Climate Dyn., 17, 327-338, doi: $10.1007 / \mathrm{s} 003820000117$.

Lu, R., 2002: Indices of the summertime western North Pacific subtropical high. Adv. Atmos. Sci., 19, 1004-1028, doi:10.1007/ s00376-002-0061-5.

Mahlstein, I., O. Martius, C. Chevalier, and D. Ginsbourger, 2012: Changes in the odds of extreme events in the Atlantic basin depending on the position of the extratropical jet. Geophys. Res. Lett., 39, L22805, doi:10.1029/2012GL053993.

Mann, H. B., 1945: Nonparametric tests against trend. Econometrica, 13, 245-259, doi:10.2307/1907187.

Matsuno, T., 1966: Quasi-geostrophic motions in the equatorial area. J. Meteor. Soc. Japan, 44, 25-43.

McGregor, S., A. Timmermann, M. H. England, O. Elison Timm, and A. T. Wittenberg, 2013: Inferred changes in El NiñoSouthern Oscillation variance over the past six centuries. Climate Past, 9, 2269-2284, doi:10.5194/cp-9-2269-2013.

Meehl, G. A., 1987: The annual cycle and interannual variability in the tropical Indian and Pacific Ocean regions. Mon. Wea. Rev., 115, 27-50, doi:10.1175/1520-0493(1987)115<0027: TACAIV $>2.0 . \mathrm{CO} ; 2$.

, 1997: The South Asian monsoon and the tropospheric biennial oscillation (TBO). J. Climate, 10, 1921-1943, doi:10.1175/ 1520-0442(1997)010<1921:TSAMAT>2.0.CO;2.

_ and J. M. Arblaster, 2002: The tropospheric biennial oscillation and Asian-Australian monsoon rainfall. J. Climate, 15, 722-744, doi:10.1175/1520-0442(2002)015<0722:TTBOAA > 2.0.CO;2.

$\longrightarrow$, - and J. Loschnigg, 2003: Coupled ocean-atmosphere dynamical processes in the tropical Indian and Pacific Ocean regions and the TBO. J. Climate, 16, 2138-2158, doi:10.1175/ 2767.1.

Menon, S., J. Hansen, L. Najarenko, and Y. Luo, 2002: Climate effects of black carbon aerosols in China and India. Science, 297, 2250-2253, doi:10.1126/science.1075159.

Nitta, T., 1987: Convective activities in the tropical western Pacific and their impact on the Northern Hemisphere summer circulation. J. Meteor. Soc. Japan, 65, 373-390. 
_ - and S. Yamada, 1989: Recent warming of tropical sea surface temperature and its relationship to the Northern Hemisphere circulation. J. Meteor. Soc. Japan, 67, 375-383.

North, G. R., T. L. Bell, R. F. Cahalan, and F. J. Moeng, 1982: Sampling errors in the estimation of empirical orthogonal functions. Mon. Wea. Rev., 110, 699-706, doi:10.1175/ 1520-0493(1982)110<0699:SEITEO > 2.0.CO;2.

Qian, C., and T. Zhou, 2014: Multidecadal variability of North China aridity and its relationship to PDO during 1900-2010. J. Climate, 27, 1210-1222, doi:10.1175/JCLI-D-13-00235.1.

_ - Z. Wu, C. Fu, and D. Wang, 2011a: On changing El Niño: A view from time-varying annual cycle, interannual variability and mean state. J. Climate, 24, 6486-6500, doi:10.1175/ JCLI-D-10-05012.1.

— Z Z. Yan, Z. Wu, C. Fu, and K. Tu, 2011b: Trends in temperature extremes in association with weather-intraseasonal fluctuations in eastern China. Adv. Atmos. Sci., 28, 297-309, doi:10.1007/s00376-010-9242-9.

Qian, W., and X. Lin, 2004: Regional trends in recent temperature indices in China. Climate Res., 27, 119-134, doi:10.3354/ cr027119.

Qian, Y., Q. Zhang, Y. Yao, and X. Zhang, 2002: Seasonal variation and heat preference of the South Asian high. Adv. Atmos. Sci., 19, 821-836, doi:10.1007/s00376-002-0047-3.

Qu, X., and G. Huang, 2012: An enhanced influence of tropical Indian Ocean on the South Asia high after the late 1970s. J. Climate, 25, 6930-6941, doi:10.1175/JCLI-D-11-00696.1.

Reiter, E. R., and D. Gao, 1982: Heating of the Tibet Plateau and movements of the South Asian high during spring. Mon. Wea. Rev., 110, 1694-1711, doi:10.1175/1520-0493(1982)110<1694: HOTTPA $>2.0 . \mathrm{CO} ; 2$.

Saji, N. H., B. N. Goswami, P. N. Vinayachandran, and T. Yamagata, 1999: A dipole mode in the tropical Indian Ocean. Nature, 401, 360-363.

Shen, S., and K. M. Lau, 1995: Biennial oscillation associated with the East Asian monsoon and tropical sea surface temperatures. J. Meteor. Soc. Japan, 73, 105-124.

Smith, T. M., R. W. Reynolds, T. C. Peterson, and J. Lawrimore, 2008: Improvements to NOAA's historical merged landocean surface temperature analysis (1880-2006). J. Climate, 21, 2283-2296, doi:10.1175/2007JCLI2100.1.

Su, B. D., T. Jiang, and W. B. Jin, 2006: Recent trends in observed temperature and precipitation extremes in the Yangtze River basin, China. Theor. Appl. Climatol., 83, 139-151, doi:10.1007/ s00704-005-0139-y.

Torrence, C., and G. P. Compo, 1998: A practical guide to wavelet analysis. Bull. Amer. Meteor. Soc., 79, 61-78, doi:10.1175/ 1520-0477(1998)079<0061:APGTWA>2.0.CO;2.

Trenberth, K. E., 1990: Recent observed interdecadal climate changes in the Northern Hemisphere. Bull. Amer. Meteor. Soc., 71, 988 993, doi:10.1175/1520-0477(1990)071<0988:ROICCI >2.0.CO;2.

Ueda, H., A. Iwai, K. Kuwako, and M. E. Hori, 2006: Impact of anthropogenic forcing on the Asian summer monsoon as simulated by eight GCMs. Geophys. Res. Lett., 33, L06703, doi:10.1029/2005GL025336.

Von Storch, H., and A. Navarra, 1995: Analysis of Climate Variability: Applications of Statistical Techniques. Springer-Verlag, $334 \mathrm{pp}$.

Wang, B., 1995: Interdecadal changes in El Niño onset in the last four decades. J. Climate, 8, 267-285, doi:10.1175/ 1520-0442(1995)008<0267:ICIENO>2.0.CO;2.
, and S. An, 2002: A mechanism for decadal changes of ENSO behavior: Roles of background wind changes. Climate Dyn., 18, 475-486, doi:10.1007/s00382-001-0189-5.

- R. Wu, and K.-M. Lau, 2001: Interannual variability of the Asian summer monsoon: Contrasts between the Indian and the western North Pacific-East Asian monsoons. J. Climate, 14, 4073-4090, doi:10.1175/1520-0442(2001)014<4073: IVOTAS $>2.0 . \mathrm{CO} ; 2$.

_ J. Yang, T. Zhou, and B. Wang, 2008: Interdecadal changes in the major modes of Asian-Australian monsoon variability: Strengthening relationship with ENSO since the late 1970s. J. Climate, 21, 1771-1789, doi:10.1175/2007JCLI1981.1.

Wang, C., and X. Wang, 2013: Classifying El Niño Modoki I and II by different impacts on rainfall in southern China and typhoon tracks. J. Climate, 26, 1322-1338, doi:10.1175/ JCLI-D-12-00107.1.

Wang, W., W. Zhou, X. Wang, S. K. Fong, and K. C. Leong, 2013: Summer high temperature extremes in southeast China associated with the East Asian jet stream and circumglobal teleconnection. J. Geophys. Res. Atmos., 118, 8306-8319, doi:10.1002/jgrd.50633.

Wang, X., D. Wang, and W. Zhou, 2009: Decadal variability of twentieth-century El Niño and La Niña occurrence from observations and IPCC AR4 coupled models. Geophys. Res. Lett., 36, L11701, doi:10.1029/2009GL037929.

$\longrightarrow,-\ldots$, and C. $\mathrm{Li}, 2012$ : Interdecadal modulation of the influence of La Niña events on mei-yu rainfall over the Yangtze River Valley. Adv. Atmos. Sci., 29, 157-168, doi:10.1007/s00376-011-1021-8.

— W. Zhou, D. Wang, and C. Wang, 2013: The impacts of the summer Asian jet stream biases on surface air temperature in mid-eastern China in IPCC AR4 models. Int. J. Climatol., 33, 265-276, doi:10.1002/joc.3419.

Wu, B., T. Zhou, and T. Li, 2009: Seasonally evolving dominant interannual variability modes of East Asian climate. J. Climate, 22, 2992-3005, doi:10.1175/2008JCLI2710.1.

- T. Li, and T. Zhou, 2010: Relative contributions of the Indian Ocean and local SST anomalies to the maintenance of the western North Pacific anomalous anticyclone during El Niño decaying summer. J. Climate, 23, 2974-2986, doi:10.1175/ 2010JCLI3300.1.

Wu, G., J. Chou, Y. Liu, Q. Zhang, and S. Sun, 2003: Review and prospect of the study on the subtropical anticyclone (in Chinese). Chin. J. Atmos. Sci., 27, 503-517.

Xiang, B., B. Wang, W. Yu, and S. Xu, 2013: How can anomalous western North Pacific subtropical high intensify in late summer? Geophys. Res. Lett., 40, 2349-2354, doi:10.1002/ grl.50431.

Xie, S.-P., K. Hu, J. Hafner, H. Tokinaga, Y. Du, G. Huang, and T. Sampe, 2009: Indian Ocean capacitor effect on Indowestern Pacific climate during the summer following El Niño. J. Climate, 22, 730-747, doi:10.1175/2008JCLI2544.1.

- , Y. Du, G. Huang, X. T. Zheng, H. Tokinaga, K. Hu, and Q. Liu, 2010: Decadal shift in El Niño influences on Indowestern Pacific and East Asian climate in the 1970s. J. Climate, 23, 3352-3368, doi:10.1175/2010JCLI3429.1.

Xin, X., R. Yu, T. Zhou, and B. Wang, 2006: Drought in late spring of South China in recent decades. J. Climate, 19, 3197-3206, doi:10.1175/JCLI3794.1.

Xu, Q., 2001: Abrupt change of the mid-summer climate in central east China by the influence of atmospheric pollution. Atmos. Environ., 35, 5029-5040, doi:10.1016/ S1352-2310(01)00315-6. 
Yan, Z., Z. Li, Q. Li, and P. Jones, 2010: Effects of site change and urbanisation in the Beijing temperature series 1977-2006. Int. J. Climatol., 30, 1226-1234, doi:10.1002/joc.1971.

_ J. Xia, C. Qian, and W. Zhou, 2011: Changes in seasonal cycle and extremes in China during the period 1960-2008. Adv. Atmos. Sci., 28, 269-283, doi:10.1007/s00376-010-0006-3.

Yang, J., Q. Liu, S.-P. Xie, Z. Liu, and L. Wu, 2007: Impact of the Indian Ocean SST basin mode on the Asian summer monsoon. Geophys. Res. Lett., 34, L02708, doi:10.1029/2006GL028571.

Yang, L., and Q. Zhang, 2007: Relationships between perturbation kinetic energy anomaly along East Asian westerly jet and subtropical high in summer (in Chinese). J. Appl. Meteor. Sci., 18, 452-459.

You, Q., S. Kang, E. Aguilar, and Y. Yan, 2008: Changes in daily climate extremes in the eastern and central Tibetan Plateau during 1961-2005. J. Geophys. Res., 113, D07101, doi:10.1029/ 2007JD009389.

- , and Coauthors, 2011: Changes in daily climate extremes in China and their connection to the large scale atmospheric circulation during 1961-2003. Climate Dyn., 36, 2399-2417, doi:10.1007/s00382-009-0735-0.

$\mathrm{Yu}, \mathrm{R}$., and T. Zhou, 2007: Seasonality and three-dimensional structure of the interdecadal change in East Asian monsoon. J. Climate, 20, 5344-5355, doi:10.1175/2007JCLI1559.1.

—, B. Wang, and T. Zhou, 2004: Tropospheric cooling and summer monsoon weakening trend over East Asia. Geophys. Res. Lett., 31, L22212, doi:10.1029/2004GL021270.

Yuan, Y., H. Yang, W. Zhou, and C. Li, 2008: Influences of the Indian Ocean dipole on the Asian summer monsoon in the following year. Int. J. Climatol., 28, 1849-1859, doi:10.1002/ joc.1678.

Zhai, P., and X. Pan, 2003: Trends in temperature extremes during 1951-1999 in China. Geophys. Res. Lett., 30, 1913, doi:10.1029/ 2003GL018004.

Zhang, P., S. Yang, and V. E. Kousky, 2005: South Asian high and Asian-Pacific-American climate teleconnection. Adv. Atmos. Sci., 22, 915-923, doi:10.1007/BF02918690.

Zhang, Q., C.-Y. Xu, Z. Zhang, G. Ren, and Y. D. Chen, 2008: Climate change or variability? The case of Yellow River as indicated by extreme maximum and minimum air temperature during 1960-2004. Theor. Appl. Climatol., 93, 35-43, doi:10.1007/s00704-007-0328-y.

Zhang, Y., X. Kuang, W. Guo, and T. Zhou, 2006: Seasonal evolution of the upper-tropospheric westerly jet core over East Asia. Geophys. Res. Lett., 33, L11708, doi:10.1029/ 2006GL026377.

Zhou, T., and R. Yu, 2005: Atmospheric water vapor transport associated with typical anomalous summer rainfall patterns in China. J. Geophys. Res., 110, D08104, doi:10.1029/ 2004JD005413.

- , and - 2006: Twentieth-century surface air temperature over China and the globe simulated by coupled climate models. J. Climate, 19, 5843-5858, doi:10.1175/JCLI3952.1.

— L. Zhang, and H. Li, 2008: Changes in global land monsoon area and total rainfall accumulation over the last half century. Geophys. Res. Lett., 35, L16707, doi:10.1029/ 2008GL034881.

—, D. Gong, J. Li, and B. Li, 2009a: Detecting and understanding the multi-decadal variability of the East Asian summer monsoon-Recent progress and state of affairs. Meteor. Z. 18, 455-467, doi:10.1127/0941-2948/2009/0396.

, B. Wu, and B. Wang, 2009b: How well do atmospheric general circulation models capture the leading modes of the interannual variability of the Asian-Australian monsoon? J. Climate, 22, 1159-1173, doi:10.1175/2008JCLI2245.1.

- and Coauthors, 2009c: Why the western Pacific subtropical high has extended westward since the late 1970s. J. Climate, 22, 2199-2215, doi:10.1175/2008JCLI2527.1.

Zhou, W., and J. C. L. Chan, 2005: Intraseasonal oscillations and the South China Sea summer monsoon onset. Int. J. Climatol., 25, 1585-1609, doi:10.1002/joc.1209.

,,-- and C. Y. Li, 2005: South China Sea summer monsoon onset in relation to the off-equatorial ITCZ. Adv. Atmos. Sci. 22, 665-676, doi:10.1007/BF02918710.

- C. Y. Li, and J. C. L. Chan, 2006: The interdecadal variations of the summer monsoon rainfall over South China. Meteor. Atmos. Phys., 93, 165-175, doi:10.1007/s00703-006-0184-9. 